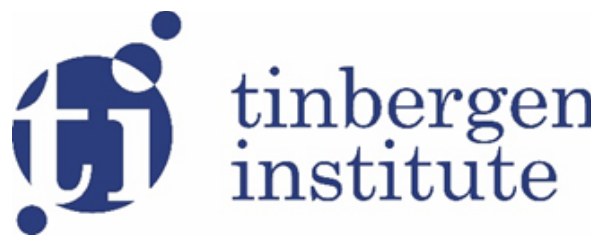

TI 2020-011/I

Tinbergen Institute Discussion Paper

\section{Gender and Willingness to Compete for High Stakes}

Thomas Buser ${ }^{1,2,3}$

Dennie van Dolder ${ }^{1,2}$

Martijn van den Assem²,4

${ }^{1}$ School of Business and Economics, Vrije Universiteit (VU) Amsterdam

2 Tinbergen Institute

${ }^{3}$ Centre for Decision Research and Experimental Economics, University of Nottingham

${ }^{4}$ Amsterdam School of Economics, University of Amsterdam 
Tinbergen Institute is the graduate school and research institute in economics of Erasmus University Rotterdam, the University of Amsterdam and Vrije Universiteit Amsterdam.

Contact: discussionpapers@tinbergen.nl

More TI discussion papers can be downloaded at https://www.tinbergen.nl

Tinbergen Institute has two locations:

Tinbergen Institute Amsterdam

Gustav Mahlerplein 117

1082 MS Amsterdam

The Netherlands

Tel.: +31(0)205984580

Tinbergen Institute Rotterdam

Burg. Oudlaan 50

3062 PA Rotterdam

The Netherlands

Tel.: +31(0)10408 8900 


\title{
Gender and Willingness to Compete for High Stakes
}

\author{
Dennie van Dolder ${ }^{1,2,3}$, Martijn J. van den Assem ${ }^{1,2}$, and Thomas Buser ${ }^{2,4}$ \\ ${ }^{1}$ School of Business and Economics, Vrije Universiteit (VU) Amsterdam \\ 2 Tinbergen Institute \\ ${ }^{3}$ Centre for Decision Research and Experimental Economics, University of Nottingham \\ ${ }^{4}$ Amsterdam School of Economics, University of Amsterdam
}

\begin{abstract}
We examine gender differences in competitiveness, using a TV game show where the winner of an elimination competition plays a game of chance worth hundreds of thousands of euros. At several stages of the competition, contestants face a choice between continuing to compete and opting out in exchange for a comparatively modest prize. When strategic considerations are absent, we observe the well-known pattern that women are less likely to compete than men, but this difference derives entirely from women avoiding competition against men. When the decision to compete is strategic and contestants should factor in the competitiveness of others, women again avoid competing against men. Men, in turn, seem to anticipate the lower competitiveness of female opponents, as evidenced by their greater tendency to compete against women. Ability differences are unlikely to explain these results. The findings underline the importance of the gender of competitors for the analysis of differences in willingness to compete, and shed new light on the persistent gender gap at the male-dominated higher rungs of the career ladder.
\end{abstract}

JEL: D91, J16

Keywords: gender differences, competitiveness, willingness to compete, game show Version: February 2020

Email addresses: d.van.dolder@vu.nl,m.j.vanden.assem@vu.nl, and t.buser@uva.nl. The paper has benefited from discussions with seminar participants at the University of Western Australia, the University of Technology Sydney, the University of New South Wales, the University of Sydney and the Bank of England, and with participants of M-BEES 2019 Maastricht and SPUDM 2019 Amsterdam. We gratefully acknowledge support from the Netherlands Organisation for Scientific Research (NWO). 


\section{Introduction}

Despite a considerable decline of the gender wage gap over the last decades, gender differences at the top have proven to be highly persistent. For example, Blau and Kahn (2017) report that in the US, the gender gap at the top of the wage distribution has declined much less than the gap at the middle and bottom of the distribution, and that in Fortune 500 companies, women make up only 14 percent of executive officers, 4 percent of CEOs, and 17 percent of board members. According to the most recent Global Gender Gap Report (World Economic Forum, 2020), worldwide only 36 percent of senior private sector managers and public sector officials are women, and only 18 percent of firms are led by a woman.

A large literature based on lab experiments suggests that these gender differences can be partially explained by competitiveness differences: relative to men, women would be more reluctant to compete (see Gneezy, Niederle and Rustichini, 2003, and Niederle and Vesterlund, 2007, for seminal contributions, and Croson and Gneezy, 2009, and Niederle and Vesterlund, 2011, for surveys). Most of the studies base their experimental design on that of Niederle and Vesterlund (2007). Participants determine how they are compensated for their performance in a series of math problems where they have to add up sets of two-digit numbers over a fixed time period. They can choose between a noncompetitive piece rate and a competitive tournament incentive scheme. If they opt for the piece rate, they earn \$1 per correct answer; if they opt for the tournament, they compete against three others, with the highest performer receiving $\$ 4$ per correct answer and the others receiving nothing. Typically, male and female subjects perform equally well on the math problems, but men are more likely to choose the competitive option. ${ }^{1}$

Compared to the financial interests that are at stake in career competitions, the money amounts used in willingness-to-compete experiments are typically very small. Notwithstanding the copious experimental evidence for the existence of a gender difference in willingness to compete, the small stakes raise the question of whether the observed behavior can be generalized to consequential realworld decisions such as competitions for boardroom positions.

The present paper uses the Dutch version of the globally successful game show format Deal or No Deal to test whether the gender difference in the willingness to enter competitions also occurs when the stakes are high. In every episode, one person plays a game of chance with an expected payoff of hundreds of thousands of euros. This finalist is selected from an audience of 500 through a series of

\footnotetext{
${ }^{1}$ Differences in willingness to compete can be driven by differences in risk attitude, (over)confidence, and attitude towards competition. In the literature, the term "competitiveness" is sometimes used in a narrow sense and then specifically refers to the latter driver. We follow Niederle and Vesterlund (2011) and use it for the overall tendency to compete.
} 
elimination games built around quiz questions. Similar to the tasks that are typically used in willingness-to-compete experiments, these quiz questions are often numerical or arithmetic in nature. In every episode, several remaining contestants are offered the option to opt out of the elimination competition in exchange for a substantial, but comparatively small prize. These high-stakes choice situations almost appear to be designed by an economist as an experiment to analyze competitiveness differences with substantial incentives.

We focus on two different games that differ in strategic complexity. In the first, contestants who most accurately answered an estimation question have to choose between competing in the next elimination game and opting out for a prize. This decision resembles the tournament-entry decision typically made by subjects in lab experiments. Mirroring the main result of Niederle and Vesterlund (2007), we find that women are more than twice as likely as men to opt out of the competition. Interestingly, the higher opt-out rate of women derives entirely from situations where the majority of their opponents in the next stage would be male. This result corroborates tentative evidence in the literature that women have a particular dislike of competition against men (Booth and Nolen, 2012; Geraldes, 2018).

The second game is a head-to-head confrontation at the end of the elimination competition. One quiz question determines the last elimination, unless one of the two contestants voluntarily accepts an optout prize. This game is more complex than the former, because the optimal choice depends on the anticipated behavior of the opponent. In the previous game, the number of competitors is predetermined, and people who want to compete do not benefit from others' reluctance to compete (contestants who opt out are replaced by another, randomly selected contestant). In this second game, however, those who choose to compete automatically win the competition if the other opts out. Such strategic interaction also plays an important role in many real-life competition choices. For example, if two colleagues are eligible for a job promotion but only one can actually get the position, both should not only factor in their comparative advantage when considering to compete for the position or not, but also the likelihood that the other will shy away from competing. Likewise, contestants who choose to compete in the head-to-head confrontation are not only betting on their relative performance, but also on the possibility that their opponent will bow out. If contestants' beliefs are based on the stereotypical view that women are less competitive than men, then both men and women will be more likely to compete against women than they will be against men. The same prediction follows from a dislike among women to compete against men-as we observe in the first game-and men being aware of women's reluctance to compete against them. 
For this second game, we find that opt-out decisions occur approximately equally often in male and female single-sex pairs, suggesting the absence of general gender difference in competitiveness. In mixed-gender pairs, however, we observe a large difference: women are about twice as likely as men to be the one who opts out. These results are consistent (i) with a lower propensity among women to compete against men than against women, as we also found for the first game, (ii) with a higher propensity among men to compete against women than against men, and (iii) with a combination of (i) and (ii). To disentangle these explanations, we exploit the temporal aspect of the game. Contestants have a limited amount of time to decide. Every second that passes until someone opts out or until the time is up is informative about the two contestants' opt-out propensities: the longer a contestant waits, the more she risks that she has to compete. Second-by-second analysis of contestants' behavior shows that both men and women have a higher propensity to compete against women. There is no evidence of a main effect of gender on competitiveness in this setting.

These results confirm that gender differences in willingness to compete also occur in situations where the stakes are very high. The stereotypical image and widely-held belief that women are less competitive than men in general, however, appears to be overly simplistic. Combined, our results suggest that women have a particular dislike of competing against men, and that men expect their female competitors to be less competitive and act accordingly in a strategic setting. In the game where strategic considerations are absent, we do observe the well-known pattern that women are more likely to avoid competition than men, but this difference derives entirely from women avoiding competition against men. There is no evidence that men condition their behavior on the gender of their opponents in the non-strategic setting. In the game where the decision to compete is strategic and contestants should factor in the competitiveness of others, women again avoid competing particularly against men. Men, in turn, seem to anticipate the lower competitiveness of their female opponents, as evidenced by their greater tendency to compete against women than against men in a strategic setting. Further analyses show that there is little reason to believe that these results are driven by gender differences in the ability to answer the questions of the various games. In particular, men and women perform roughly equally well in the actual tasks.

The findings shed new light on the persistent gender gap at the higher rungs of the career ladder. Typically, the competitor pool gradually becomes more male-dominated the closer one gets to the top. If women are more likely to give up when faced with a male competitor and men compete harder when faced with a female competitor, male dominance in professional environments could become self-perpetuating. 
With the use of a combination of high stakes and a quasi-controlled setting we complement recent work that attempts to assess the external validity of competitiveness differences found in the lab. Various studies show that measurements for subjects in the lab can explain differences between the same subjects in important real-world outcomes: decisions to compete or not compete in the lab are found to correlate with education and career choices, and with labor market success (Zhang, 2013; Buser, Niederle and Oosterbeek, 2014; Berge et al., 2015; Almås et al., 2016a; Buser, Peter and Wolter, 2017a, 2017b; Buser, Geijtenbeek and Plug, 2018; Reuben, Sapienza and Zingales, 2019; Buser, Niederle and Oosterbeek, 2020). More directly, in field experiments where individuals apply for real jobs, Flory, Leibbrandt and List (2015) and Samek (2019) document gender differences in the willingness to work under competitive incentive schemes. Our naturally occurring experiment offers more control than the first set of studies, and substantially higher stakes than the second.

Hitherto, the literature on gender differences in the willingness to compete has largely ignored the potential importance of the gender composition of the competitor base. Notable exceptions are the studies of Booth and Nolen (2012) and Geraldes (2018), which use the Niederle and Vesterlund (2007) experimental paradigm and similarly find that women are less willing to compete against men than against women. Strategic interaction is typically ruled out by design in willingness-to-compete experiments, and how gender differences play out when the optimal choice depends on the anticipated behavior of competitors has therefore received even less attention. ${ }^{2}$ This neglect is surprising in the light of the evidence that women perform worse when they compete with men (Gneezy, Niederle and Rustichini, 2003; Günther et al., 2010; Backus et al., 2016; de Sousa and Hollard, 2016; Booth, Cardona-Sosa and Nolen, 2018; Booth and Yamamura, 2018). Our study underlines the importance of considering the gender composition of the competitor base when investigating gender differences in willingness to compete.

Our paper adds to a long list of papers that have employed TV game shows for the study of decision making. Starting in the 1990s, researchers have used the behavior of contestants to investigate, for example, risky choice (Gertner, 1993; Metrick, 1995; Post et al., 2008), strategic reasoning (Bennett and Hickman, 1993; Berk, Hughson and Vandezande, 1996; Tenorio and Cason, 2002), discrimination (Levitt, 2004; Antonovics, Arcidiacono and Walsh, 2005; Belot, Bhaskar and van de Ven, 2012), cooperation (List, 2006; Oberholzer-Gee, Waldfogel and White, 2010; van den Assem, van Dolder and Thaler, 2012; Turmunkh, van den Assem and van Dolder, 2019), and bargaining (van Dolder et al.,

\footnotetext{
${ }^{2}$ An exception is Datta Gupta, Poulsen and Villeval (2013), who use an experimental design that is close to our head-to-head game. In their data there is suggestive evidence that men compete more against women: out of the eight males who faced a female opponent, five chose to compete (62.5\%), whereas out of the twelve males who faced a male opponent, only four chose to compete (33.3\%).
} 
2015). The existing game show study that is closest to ours is Hogarth, Karelaia and Trujillo (2012). They analyze the Colombian game show "El Jugador", which is built around a game that closely resembles the elimination game examined in the appendix of the present study. In line with our results, they report that women voluntarily exit the game more often than men, especially when in a minority.

The paper proceeds as follows. Section 2 describes the Dutch version of Deal or No Deal in more detail, and discusses our data. Sections 3 and 4 cover the descriptions and analyses of the two different games of interest. Section 5 asks whether the results can be explained by gender differences in performance. Section 6 concludes.

\section{Game show and data}

The common and main part of all editions of the globally successful game show format Deal or No Deal is a high-stakes game that involves simple stop-go choices between accepting a sure amount and risky continuation. This game is played by one contestant, who "owns" one sealed case-a briefcase or a box-out of a larger set of sealed cases that each contain a money prize. The prizes differ across editions, but are always known at the start and always strongly right-skewed. Each round, the contestant opens a given number of cases and consequently learns which amounts are not in her own case. At the end of every round, a hypothetical "banker" makes an offer to buy her case, which she can then accept ("Deal") or decline ("No Deal"). The game continues either until an offer is accepted, or until all cases are opened and the contestant receives the prize in her own case. Deal or No Deal can be considered as a naturally occurring risky choice experiment and has been exploited as such by many, including Deck, Lee and Reyes (2008), Post et al. (2008), Brooks et al. (2009), Blavatskyy and Pogrebna (2010), de Roos and Sarafidis (2010), and Bombardini and Trebbi (2012).

The Dutch version of Deal or No Deal is called "Miljoenenjacht" (translated: "Chasing Millions"). This version is unique because of the elimination competition that precedes the main game, and because the prizes are considerably larger than those in other editions. Each episode starts with 500 contestants, and after various elimination games, the one remaining contestant in expectation takes home hundreds of thousands of euros. The Dutch edition owes its large stakes to the Dutch Postcode Lottery, which pays out all prizes as a part of their payout scheme. All 500 initial contestants have won their ticket through this lottery. ${ }^{3}$ In addition to the lucrative possibility of becoming the finalist,

\footnotetext{
${ }^{3}$ A substantial fraction of the Dutch population take part in the Dutch Postcode Lottery. In 2017, for example, there were 7.8 million Dutch households, and 2.9 million participated. Sources: Annual Report 2017 Dutch Postcode Lottery, CBS Statline.
} 
contestants can win several other large prizes. These are either allocated randomly or awarded as an opt-out prize.

The first episode was aired on December 22, 2002. At the time of writing, the game show is still running. Our analysis uses the complete set of 183 episodes aired between inception and March 31, 2019. In this time span, there were 33 short series of weekly episodes, and 6 individual episodes on either New Year's Eve or New Year's Day. Most were recorded by the authors, and videotapes of early episodes were obtained from a Dutch broadcasting company. The average of the set of 26 money prizes in the final varied between $€ 391,411$ in early episodes and $€ 516,122$ in later episodes. The largest prize was always five million euros. Most contestants sold their case at some point, at a discount relative to the expected value. On average, a finalist took home $€ 233,761$.

At the start of every elimination game, the 500 contestants are seated in the audience together with a friend or relative. To arrive at the final contestant, various elimination games are played. Figure 1 gives a schematic overview of the different games and how these were combined over time and episodes; thumbnail descriptions are in the notes. Games marked with one or two asterisks featured at least one opt-out opportunity. We analyze the opt-out decisions in games marked with two asterisks.

Because of small sample sizes and lack of choice variation we exclude the games labeled A1 and A3. In game $A 1$, which lasted for 33 episodes, one randomly selected eliminated contestant was offered the choice between re-entering the competition and a prize worth between approximately $€ 5 \mathrm{k}$ and $€ 10 \mathrm{k}$. The option to re-enter was absent in the very first episode, leaving a total of 32 observations for this game. Only two males (out of 21 , or $10 \%$ ) and two females (out of 11 , or $18 \%$ ) opted out. Similarly, in game $\mathrm{A} 3$, three randomly selected eliminated contestants could either re-enter or accept a prize package worth between approximately $€ 1 \mathrm{k}$ and $€ 15 \mathrm{k}$. That game lasted for only five episodes, and in all fifteen occasions the contestant chose to re-enter the competition.

We leave game $\mathrm{C}$ out of consideration because of its complexity and relatively small sample size. At the start of this game there were six contestants left. In each of four rounds, the contestant first to press her button answered a quiz question. If her answer was incorrect, she was eliminated. If her answer was correct, she designated one of the other contestants for elimination. Prior to the revelation of the name of the targeted contestant, contestants had to choose between a monetary opt-out prize (average value: $€ 10 k$ ) and continuing, with the risk of being the one sent home empty-handed. Twelve episodes featured this game, and in total there were 41 cases where contestants faced the possibility 


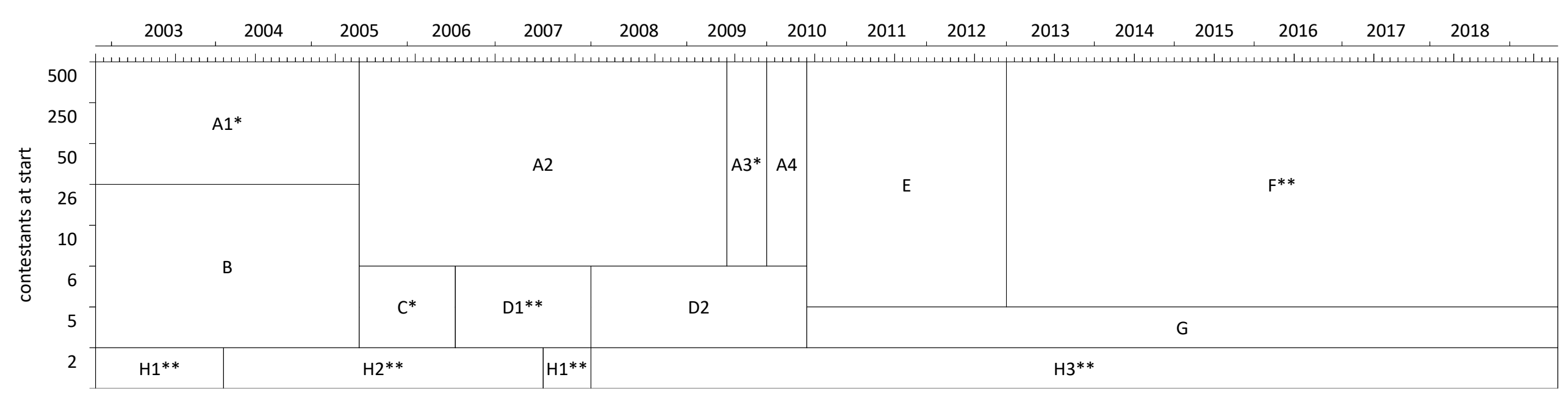

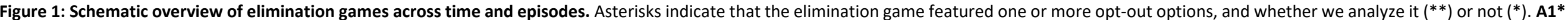

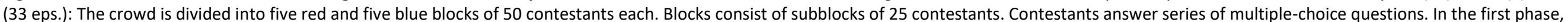

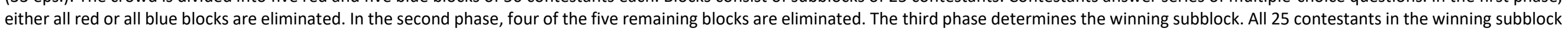

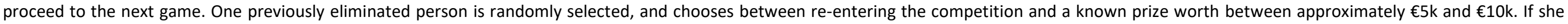

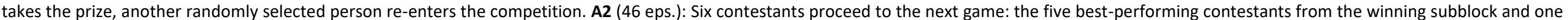

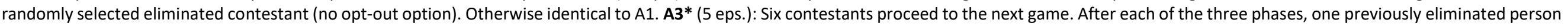

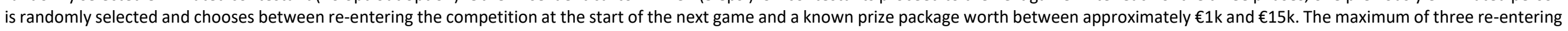

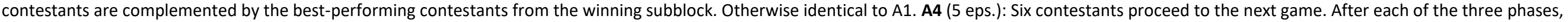

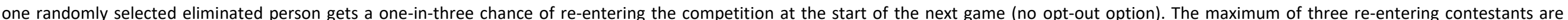

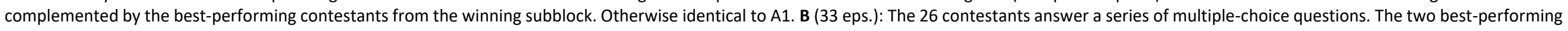

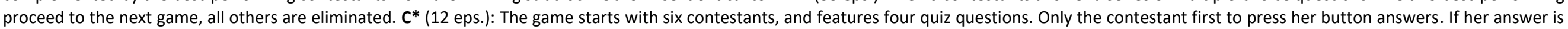

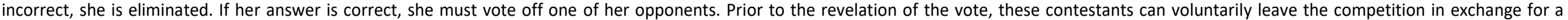

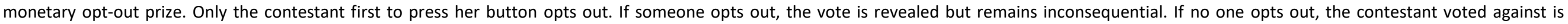

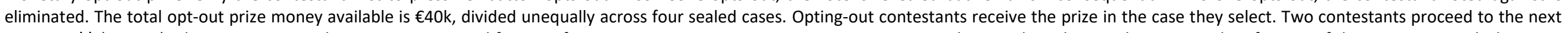

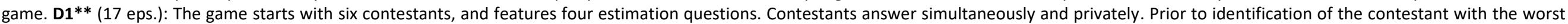

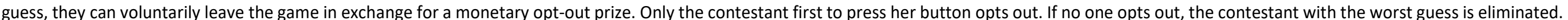

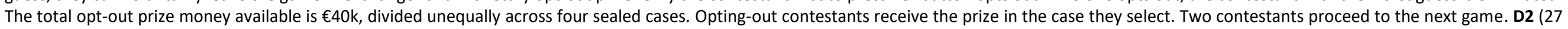

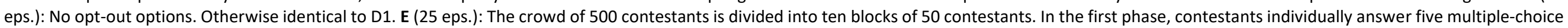

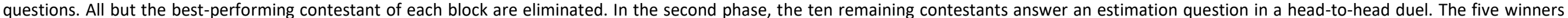

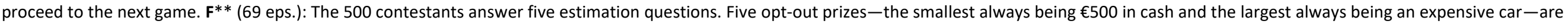

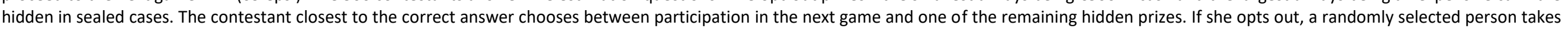

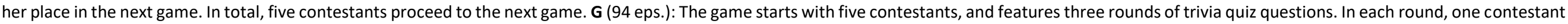

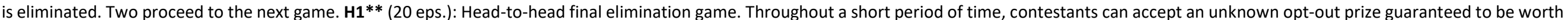

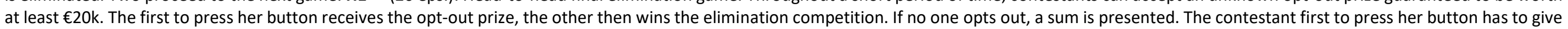

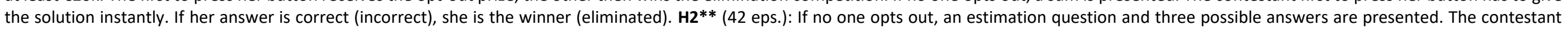

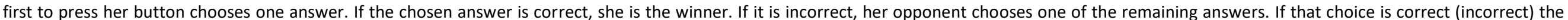

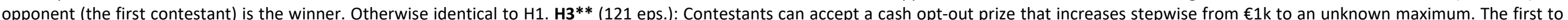
press her button fixes and receives the money amount, the other then wins the elimination competition. Otherwise identical to $\mathrm{H} 1$. 
to opt out. For a proper analysis of this game, we need to take account of differences in contestants' probability of being nominated for elimination. Unfortunately we have insufficient data to reliably perform such an analysis.

Game D1 is described and analyzed in the Appendix. Through four estimation questions, this game narrowed a group of six contestants down to two. Contestants answered each estimation question simultaneously and privately. Prior to identification of the contestant with the worst guess, they could voluntarily leave the game in exchange for a monetary opt-out prize (average value: €10k). Only the contestant first to press her button opted out. If no one opted out, the contestant with the worst guess was eliminated. This game is in the Appendix for two reasons. First, the sample size is relatively small (17 episodes, 68 opt-out opportunities). Second, because of a censoring problem -if a contestant opts out it remains unknown what the other contestants would have done-we are unable to draw clear conclusions. Nevertheless, the patterns that we observe are in line with the results for the two games that are the focus of our study.

The games featuring the opt-out options that we analyze in the next two sections are represented in Figure 1 as F and H1-3. Game F reduced the initial crowd from 500 to five, and is described and analyzed in Section 3. Games H1-3 are variants of the two-person game that determined the last elimination of every elimination competition, and these are described and analyzed in Section 4.

Clearly, the stakes in the decisions that we study are high. Contestants are competing for the unique opportunity to play a game that offers life-changing amounts of prize money. Would we have run the two elimination games that we analyze and the subsequent finals as an experiment ourselves, the total cost in subject payoffs alone would have been nearly $€ 50$ million (accepted opt-out prizes: $€ 4.8 \mathrm{~m}$; money won in the final: €42.8m).

\section{Game one: From 500 to 5}

\section{Description and data}

From 2013 onwards, the initial crowd of 500 contestants was reduced to five through five estimation questions. Examples are "How many ambulances are there in the Netherlands?" and "How many words does the first verse of the Dutch National Anthem have?". For each of the five questions, the person closest to the correct answer (and the fastest in the case of a tie) was offered a choice between one of the five seats in the next elimination game and one of the opt-out prizes that were hidden in five large numbered briefcases. The smallest and largest opt-out prize were always a monetary amount of $€ 500$ and an expensive car (mostly worth roughly $€ 50 k$ ). The other three varied across episodes, and 
had a value between approximately $€ 2 \mathrm{k}$ and $€ 10 \mathrm{k}$ (examples are gift cards, holidays, electronics, and city cars). If the winning contestant chose the seat, one of the remaining cases was randomly assigned to someone else in the audience. If the winning contestant opted out, the seat left vacant was similarly given to someone else. Contrary to the game in the next section (and that in the Appendix), there is no strategic interaction in this game. In this sense, the decisions are close to the tournament-entry decisions in typical willingness-to-compete experiments.

We collected the data for all 344 choices between a seat and an opt-out prize made in the 69 episodes featuring this elimination game. ${ }^{4}$ The average age of the contestants was 49 years ( $\min : 21$, max: 81). The majority was male (208 out of 344 , or $60.5 \%$ ).

\section{Analyses and results}

Most contestants prefer taking the seat in the next stage over picking an opt-out prize: the overall optout rate is $18.9 \%$. As illustrated by Figure $2 \mathrm{a}$, women are approximately twice as likely as men to opt out (women: $27.9 \%$, men: 13.0\%; $\operatorname{Ch}^{2}(1)=12.010, p=0.001$ ).

We estimate a multivariate linear probability model to control for variation in contestants' age, the attractiveness of the remaining opt-out prizes, and the question number. The dependent variable takes the value of one if the contestant opts out (and zero otherwise). We include a quadratic specification for age, because the raw data suggest a u-shaped relationship. ${ }^{5}$ Age is an integer, measured in years and centered on the mean. We use two variables to control for the attractiveness of the set of remaining opt-out prizes: the probability of winning the expensive car, and the probability of winning the small cash prize of $€ 500$. Last, we include question-number fixed effects because seats in the next stage are allocated in order of attractiveness (the most attractive seats first). We correct the standard errors for clustering at the episode level.

Table 1, Model 1 presents the results. The regression results closely match the raw comparisons of opt-out rates: after controlling for the effects of age, the attractiveness of the remaining prizes, and question-number fixed effects, women are 15.6 percentage points more likely to opt out than men. The regression results also confirm the u-shaped effect of age: the estimates imply that the opt-out

\footnotetext{
${ }^{4}$ Normally there were five choices per episode. In one episode, however, one contestant gave the best response to two estimation questions. Because she had already taken a seat in the next stage after the first question, she had no choice but to pick one of the remaining briefcases with an opt-out prize after the second.

${ }^{5}$ The opt-out rate is $19.0 \%$ for contestants younger than 40 years, $8.3 \%$ for contestants between 40 and 50 years, $18.2 \%$ for contestants between 50 and 60 years, and $35.2 \%$ for contestants 60 years or older.
} 

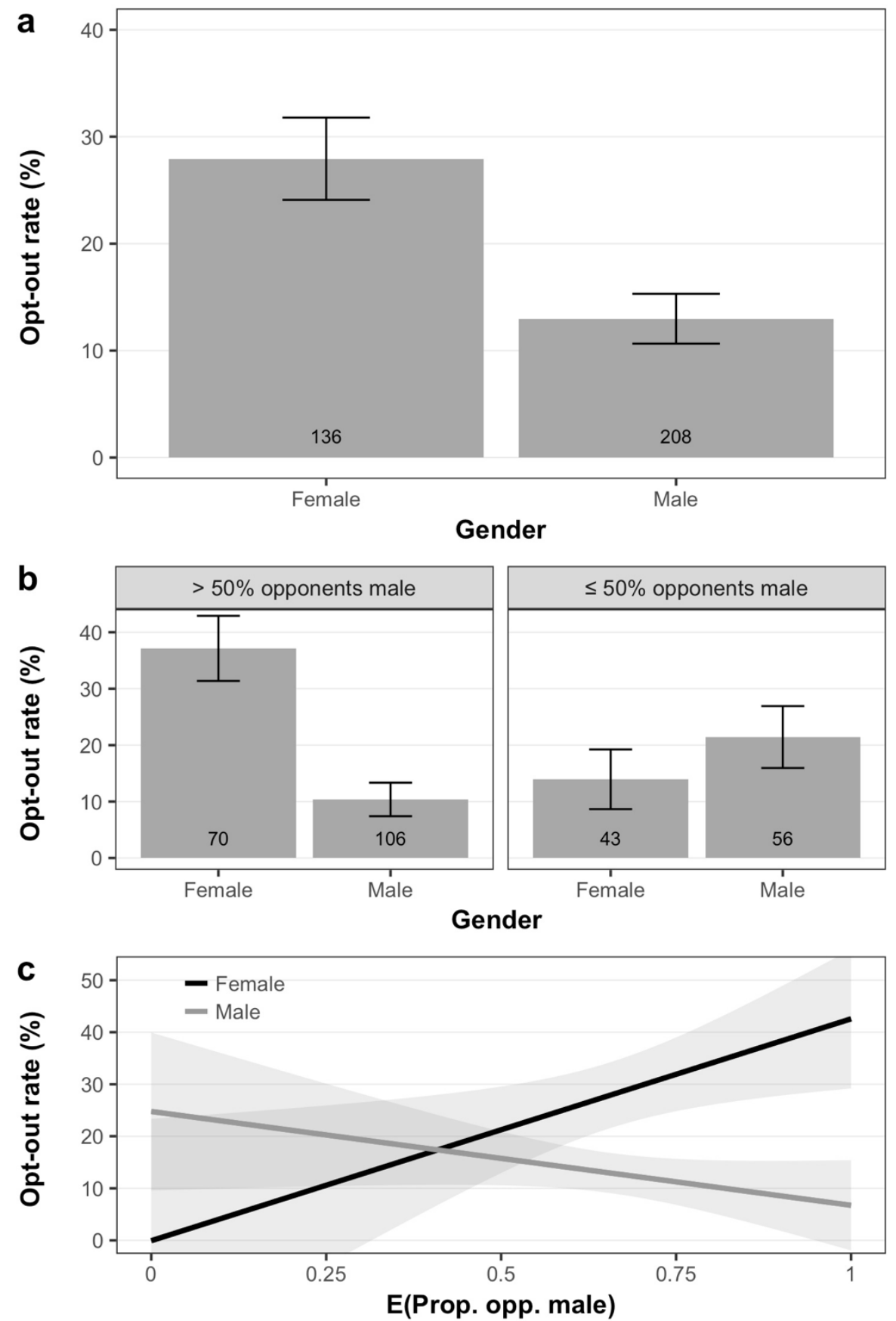

Figure 2: Opt-out rates for men and women in game one. (a) displays the opt-out rates for male and female contestants, measured across all questions. (b) displays the opt-out rates for male and female contestants across questions $2-5$, conditional on whether more than half of the previously selected competitors for the next stage of the elimination competition are male ( $>50 \%$ opponents male), and conditional on whether half or more of the previously selected competitors are female ( $\leq 50 \%$ opponents male) at the time the contestant makes her opt-out decision. The number of observations is at the bottom of each bar. Error bars depict standard errors around the mean. (c) displays the univariate linear relationship between the opt-out rate and the expected proportion of male opponents, estimated across all questions, for male and female contestants separately. The shaded areas represent $90 \%$ confidence intervals. 


\section{Table 1: Regression results for game one}

The table displays results from regression analyses of contestants' decisions to opt out (1) or not (0) in the first game. Female is a dummy variable that takes the value of 1 if the contestant is female. Age is the contestant's age, measured in years and centered on the mean (48.7y). Majority opp. male is a dummy variable that takes the value of 1 if the majority of already selected competitors are male, and is missing if no competitors are selected yet. E(Prop. opp. male) is the expected proportion of male opponents, centered on the mean. $P(\mathrm{Car})$ is the probability that a contestant who opts out wins the expensive car. $P$ (Small prize) is the probability that a contestant who opts out wins the small prize of $€ 500$. All models include question-number fixed effects. Standard errors (in parentheses) are corrected for clustering at the episode level. Asterisks denote statistical significance at the one $* * *$, five ${ }^{* *}$ and ten $*$ percent level, respectively.

\begin{tabular}{|c|c|c|c|c|c|}
\hline & Model 1 & Model 2 & Model 3 & Model 4 & Model 5 \\
\hline \multirow[t]{2}{*}{ Female } & $0.156 * * *$ & $0.148 * *$ & -0.033 & $0.156^{* * *}$ & $0.156 * * *$ \\
\hline & $(0.051)$ & $(0.060)$ & $(0.078)$ & $(0.051)$ & $(0.046)$ \\
\hline \multirow[t]{2}{*}{ Age } & $0.004 * *$ & $0.004 * *$ & $0.004 * *$ & $0.004 * *$ & $0.004 * *$ \\
\hline & $(0.002)$ & $(0.002)$ & $(0.002)$ & $(0.002)$ & $(0.002)$ \\
\hline \multirow[t]{2}{*}{$\mathrm{Age}^{2} / 100$} & $0.035 * * *$ & $0.031 * * *$ & $0.027 * *$ & $0.035^{* * *}$ & $0.033^{* * *}$ \\
\hline & $(0.010)$ & $(0.010)$ & $(0.011)$ & $(0.010)$ & $(0.010)$ \\
\hline \multirow[t]{2}{*}{ Majority opp. male } & & 0.012 & -0.109 & & \\
\hline & & $(0.043)$ & $(0.066)$ & & \\
\hline \multirow[t]{2}{*}{ Female x Majority opp. male } & & & $0.289 * * *$ & & \\
\hline & & & $(0.108)$ & & \\
\hline \multirow[t]{2}{*}{ E(Prop. opp. male) } & & & & 0.054 & -0.158 \\
\hline & & & & $(0.096)$ & $(0.148)$ \\
\hline \multirow[t]{2}{*}{ Female x E(Prop. opp. male) } & & & & & $0.495^{* *}$ \\
\hline & & & & & $(0.247)$ \\
\hline \multirow[t]{2}{*}{$\mathrm{P}($ Car $)$} & $0.309 * * *$ & $0.305^{* * *}$ & $0.311^{* * *}$ & $0.310 * * *$ & $0.304 * * *$ \\
\hline & $(0.100)$ & $(0.101)$ & $(0.102)$ & $(0.102)$ & $(0.103)$ \\
\hline \multirow[t]{2}{*}{$\mathrm{P}($ Small prize $)$} & $-0.202 * * *$ & $-0.204 * * *$ & $-0.202 * * *$ & $-0.199 * * *$ & $-0.204 * * *$ \\
\hline & $(0.074)$ & $(0.073)$ & $(0.073)$ & $(0.073)$ & $(0.074)$ \\
\hline Question-number fixed effects & yes & yes & yes & yes & yes \\
\hline Data included & all & questions 2-5 & questions 2-5 & all & all \\
\hline$R^{2}$ & 0.153 & 0.152 & 0.180 & 0.153 & 0.165 \\
\hline No. of observations & 344 & 275 & 275 & 344 & 344 \\
\hline No. of episodes & 69 & 69 & 69 & 69 & 69 \\
\hline
\end{tabular}

rate decreases with age if the contestant is younger than 43 years, and increases with age for older contestants. As expected, contestants are more likely to opt out if the chance of winning the car is higher, and less likely to opt out if the chance of winning the small money amount is higher.

Recent evidence suggests that women have a special dislike of competing against men (Booth and Nolen, 2012; Geraldes, 2018). In our setting, the contestant who decides following the first estimation question does not yet know the gender of her competitors in the next game, but those who make their choice after successfully answering one of the other four questions do know the gender of some (questions 2-4) or all (question 5) competitors. To investigate whether men and women condition their opt-out decision on the gender composition of the existing set of competitors, we distinguish between 
situations where most of the occupied seats in the next game are taken by men ( $>50 \%$ male) and situations where half or more of the seats are taken by women ( $\leq 50 \%$ male) at the time the contestant makes her opt-out decision. ${ }^{6}$ Because of the higher proportion of male contestants in the initial crowd and because of the higher opt-out rate among women, a majority (177 out of 276 , or $64.1 \%$ ) was facing predominantly male opponents when they had to make their decision.

Figure $2 \mathrm{~b}$ depicts the opt-out rates for men and women across questions $2-5$, conditional on whether most of the previously selected competitors are male and conditional on whether half or more are female. The differences are large. Women are significantly more likely to opt out than men if the majority of filled seats are occupied by men (women: 37.1\%, men: $10.4 \% ; \operatorname{Chi}^{2}(1)=18.191, p<0.001$ ). If at least half of the seats are taken by women, however, the opt-out rates of men and women are statistically not significantly different (women: $14.0 \%$, men: $21.4 \% ; \operatorname{Ch}^{2}(1)=0.913, p=0.339$ ). Based on these opt-out rates, both men and women seem to dislike competing against the opposite sex: if more than half of the previously selected opponents are male, women are significantly more likely to opt out (> 50\% male: $37.1 \%, \leq 50 \%$ male: $14.0 \%$; $\operatorname{Chi}^{2}(1)=7.056, p=0.008$ ), and men are marginally significantly less likely to opt out (> 50\% male: $10.4 \%, \leq 50 \%$ male: $21.4 \%$; $\operatorname{Chi}^{2}(1)=3.674, p=0.055$ ) as compared to situations where at least half are female.

In Table 1, Model 2 adds a dummy variable to the regression analysis that takes the value of one if more than half of the previously selected opponents is male (and zero otherwise), and shows that there is no significant main effect of gender composition on opt-out rates $(p=0.782)$. Model 3 adds the interaction of this dummy variable with the contestant's own gender. In line with the raw statistics, men and women respond significantly different to the gender composition $(p=0.009)$. Women are 18.0 percentage points more likely to opt out if the majority of already selected contestants are male as compared to situations where half or more are female $(-0.109+0.289=0.180 ; p=0.013)$. Men, in contrast, are 10.9 percentage points less likely to opt out when the majority of selected opponents are male as compared to situations where half or more are female, but statistically this difference is not significant $(p=0.104)$. The opt-out rates differ significantly between men and women in maledominated environments only: women are 25.6 percentage points more likely to opt out than men when the majority of selected opponents is male $(-0.033+0.289=0.256 ; p=0.001)$, but statistically neither more nor less likely to opt out when half or more is female $(p=0.676)$.

\footnotetext{
${ }^{6} \mathrm{~A}$ player who makes her opt-out decision after question $i$ knows the identity of $i-1$ competitors. The majority of seats are therefore filled by male contestants if $1 / 1$ is taken by a man after question 2 , if $2 / 2$ are taken by men after question 3 , if $2 / 3$ or $3 / 3$ are taken by men after question 4 , and if $3 / 4$ or $4 / 4$ are taken by men after question 5.
} 
The binary division of whether more or less than half of already selected opponents are male is rather crude, and also neglects that the ultimate composition depends on the gender of the opponents who take the remaining vacant seats. We therefore also investigate the effect of gender composition by looking at the expected proportion of males among the total of four competitors in the next elimination game. Across all episodes, 219 out of the 345 contestants who proceed to the next stage are male (63.5\%). To calculate the expected number of male opponents at the moment a contestant makes her opt-out decision, we adopt this proportion and assume that the likelihood that a vacant seat is taken by a male (female) is $0.635(0.365)$. Figure $2 c$ shows the linearly fitted relationship between the opt-out rate and the expected proportion of male opponents, for male and female contestants separately. The graph indicates that the difference in opt-out rates between men and women reaches statistical significance only if the expected proportion of male opponents is high.

In Table 1, Model 4 includes the expected proportion of males as a regressor, and shows again that there is no significant main effect of gender composition on contestants' opt-out propensity $(p=0.575)$. Model 5 adds the interaction of the expected proportion of males and contestants' own gender, and confirms that men and women respond differently to the expected gender composition $(p=0.049)$. If the expected proportion of male opponents increases by $0.25-$ an increase that corresponds to one additional male opponent-women become 8.4 percentage points more likely to opt out $(0.25 \times-0.158+0.25 \times 0.495=0.084 ; p=0.045)$, while the opt-out propensity of men is not significantly affected $(0.25 \times-0.158=-0.040 ; p=0.289)$. The opt-out rate of men and women is statistically significantly different at the five percent level if the expected proportion of male opponents exceeds fifty percent.

In summary, the results for this first game confirm that the gender difference in willingness to enter competitions-robustly found in lab and classroom experiments with low stakes-is also present in an environment with very high monetary stakes: 13 percent of men and 28 percent of women choose to opt out of the competition in return for a relatively modest prize. Interestingly, the comparatively high opt-out rate of women derives entirely from situations where the majority of their opponents are (or are expected to be) male, which suggests that women have a particular dislike of competition against men, rather than a higher general aversion to competition. 


\section{Game two: Head to head}

\section{Description and data}

At the very last stage of every elimination competition there are two contestants left. Only one of them will play Deal or No Deal, the game of chance worth hundreds of thousands of euros. A final question determines the last elimination, unless one of the two contestants voluntarily accepts an opt-out prize to avoid the head-to-head confrontation and the risk of leaving empty-handed. This opportunity to opt out starts as soon as the light bulb located in between the two contestants turns green, and lasts only briefly. As long as the light bulb is green, one of them can accept the prize by being the first to hit a button located within their reach. If no one moves and the light turns red, indicating that the possibility to opt out is over, the two contestants proceed to the decisive question.

In contrast to the previous section, the opt-out decisions studied here are of a strategic nature. If one of the contestants opts out, the other automatically proceeds to the lucrative final. Contestants should therefore not just consider their willingness to bet on their ability to beat their opponent in the final question, but also the likelihood that their opponent will opt out.

All 183 episodes featured a variant of this game. In Figure 1, these are represented as $\mathrm{H} 1, \mathrm{H} 2$ and $\mathrm{H} 3$. In the first 62 episodes ( $\mathrm{H} 1$ and $\mathrm{H} 2$ ), the exact opt-out prize was unknown to the contestants, but guaranteed to be worth at least $€ 20,000$. Frequently, the prize turned out to be an expensive car (mostly worth roughly $€ 50,000$ ). Other common prizes were luxurious trips (often with pocket money or a suitcase set included), electronics packages, and gift cards for traveling, jewelry, or furniture. In 23 episodes (37\%) one of the two contestants opted out. This happened after 3 seconds on average (min: 1s; max 9s). When no one budged (39 episodes; 63\%), the maximum time available for opting out varied between 6 and 17 seconds (avg: 9s).

In the remaining 121 episodes (H3), contestants could opt out for a cash prize that increased stepwise from $€ 1,000$ to a predetermined maximum. This maximum was unknown to the contestants, and ranged between $€ 20,000$ and $€ 108,000$ (avg: $€ 51,470$ ). The first contestant to press her button stopped the clock and received the cash prize. In 78 episodes (64\%), one of the two contestants opted out, for an amount between $€ 16,600$ and $€ 70,900$ (avg: $€ 38,712$ ). This happened after 28 seconds on average (min: 8s; max 45s). In the other 43 episodes, in which nobody pressed the button, the time window during which the opt-out prize kept increasing lasted for between 19 and 55 seconds (avg: $32 \mathrm{~s})$.

In 143 episodes ( $\mathrm{H} 1$ and $\mathrm{H} 3$ ), the decisive question was (or would have been) a relatively simple math problem. Examples are " $356+147=$ ?", “4 x $44=$ ?”, and "314 - $118=$ ?”. The first contestant to press 
her button had to give the solution instantly. If her answer was correct, she was the winner and subsequently played Deal or No Deal. If her answer was incorrect, she was eliminated and the other contestant played the final game. The given answers were correct in 39 out of 54 attempts (72\%).

In the remaining 40 episodes $(\mathrm{H} 2)$, the decisive question was (or would have been) an estimation question. Contestants could choose from three possible answers. The first to press her button chose first. If the chosen answer was correct, she was the winner. If the chosen answer was incorrect, her opponent chose one of the two remaining answers. If that choice was correct, this second contestant was the winner. If it was incorrect, the first contestant would proceed to the final game. First attempts were correct 7 out of 28 times (25.0\%), second attempts 11 out of 21 times (52.4\%).

We collected the data for this elimination game for all 183 episodes. Owing to the introductory talk of the game show host with the two contestants, we could also estimate each contestant's level of education. Education is usually not explicitly mentioned, but it is often clear from the stated profession. We coded education as a dummy variable, with a value of one assigned to contestants with a bachelor's degree level or higher (including students) or equivalent work experience.

The majority of the contestants were male ( 255 out of 366 , or $61.9 \%$ ). The average age was 46 years (min: 21, max: 86), and 38.0 percent were high-educated (139 out of 366). An opt out occurred in 55.2 percent of the episodes (101 out of 183).

\section{Analyses and results}

Across all episodes combined, women opt out more frequently than men, but this difference is not statistically significant: 45 out of 141 women (31.9\%) and 56 out of 225 men (24.9\%) at some point press their button $\left(\mathrm{Chi}^{2}(1)=2.14, p=0.143\right)$.

Of the 183 pairs that we observe, 24 consist of two women (13.1\%), 66 consist of two men (36.1\%), and 93 are mixed (50.8\%). Figure 3 depicts the opt-out rates of men and women for the different kinds of pairs. In mixed-gender pairs, women are almost twice as likely to opt out as men (women: $36.6 \%$, men: $\left.20.4 \% ; \operatorname{Chi}^{2}(1)=5.937, p=0.015\right)$. On the other hand, women facing a woman do not opt out significantly more frequently than men facing a man (women vs. woman: $22.9 \%$, men vs. man: $28.0 \%$; $\left.\operatorname{Chi}^{2}(1)=0.471, p=0.493\right)$. These two comparisons suggest that opt-out decisions depend on the gender of the opponent. 

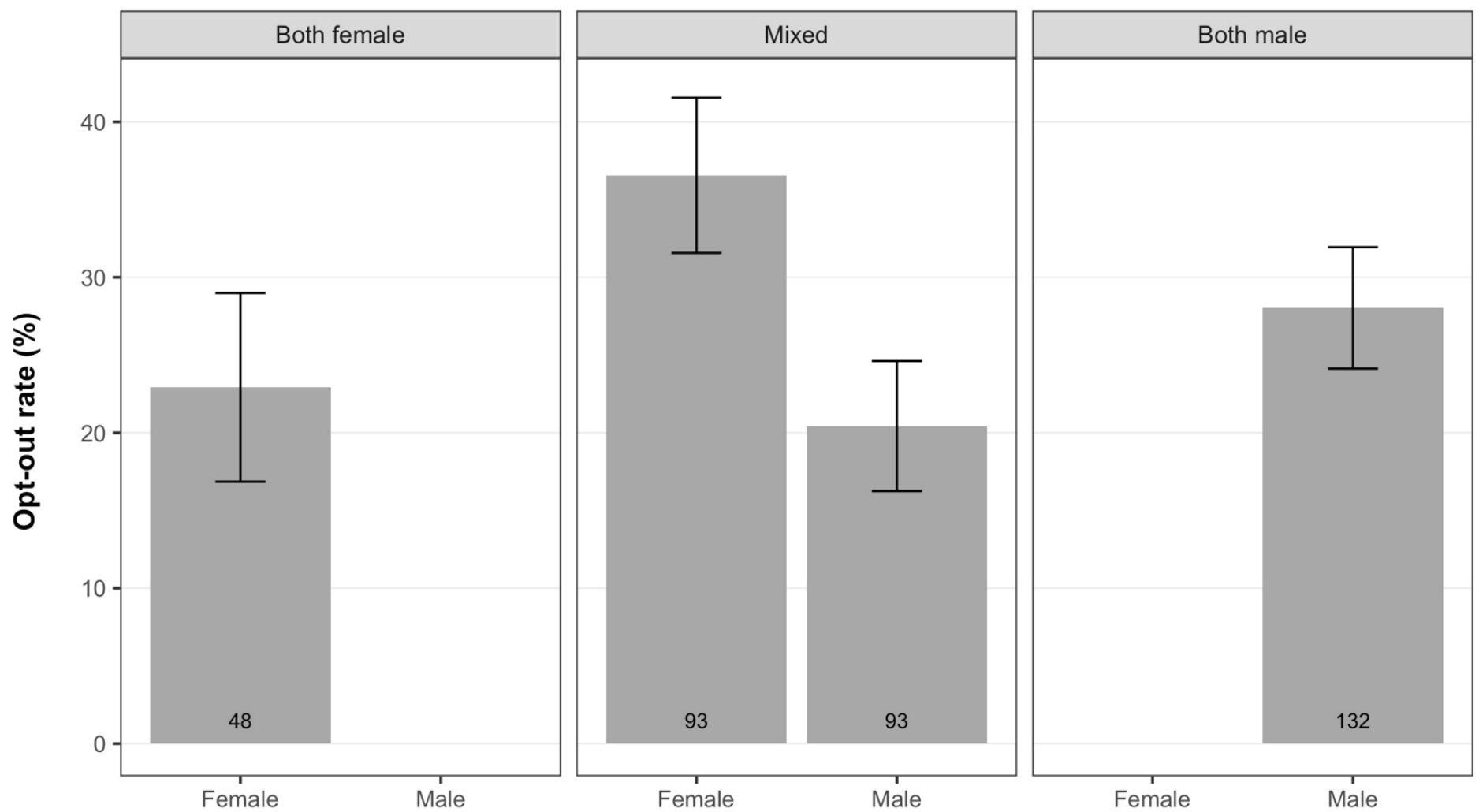

Gender

Figure 3: Opt-out rates for men and women in game two. The figure displays the opt-out rates for male and female contestants, separately for female-female (both female), female-male (mixed), and male-male (both male) pairs. The number of observations is at the bottom of each bar. Error bars depict standard errors around the mean.

We cannot use simple comparisons to examine how men and women respond to the gender of their opponent. The present game comes with a censoring problem: at most one of the two contestants can opt out, and we do not observe what a contestant whose opponent opts out would have done if her opponent had not opted out. Consequently, observed opt-out rates do not only depend on contestants' own opt-out propensity, but also on that of their opponents. For example, if women always immediately opt out when they face a man, we would mechanically observe an opt-out rate of zero for men who face a woman. If the opt-out intentions of men are not affected by the gender of their opponent, a simple comparison of the behavior of men in the two possible situations-men facing a man vs. men facing a woman-would wrongly suggest that such a dependency does exist.

To deal with this censoring issue, we analyze the behavior of contestants on a second-by-second basis. Contestants can wait for an unknown but considerable amount of time in the hope that the other opts 
out. Every second that passes until either someone opts out or time runs out is informative about the two contestants' opt-out propensities: the longer a contestant waits, the more she risks that she has to compete.

We exploit this temporal aspect of the game with a Cox proportional hazards approach (Cox, 1972), and study contestants' decisions to opt out or not during all seconds in which they were able to make this decision. ${ }^{7}$ The format of the elimination game with the unknown prize $(\mathrm{H} 1$ and $\mathrm{H} 2)$ differs substantially from the elimination game with the increasing cash prize (H3), and therefore we allow the baseline hazard to differ between these two variants. Furthermore, the models include a dummy variable to distinguish between games where the decisive question is (or would be) a sum and games featuring a multiple-choice estimation question, and a variable that equals the natural logarithm of the predetermined maximum opt-out cash prize for games where the opt-out prize increased stepwise (H3). ${ }^{8}$ In addition, we include a quadratic specification for age, and a dummy variable for education that differentiates between those with at least a bachelor's degree and those without. Last, we correct the standard errors for clustering at the episode level.

Table 2 presents the results. Model 1 considers all pairs and confirms the descriptive result there is no significant gender difference in opt-out rates $(p=0.555)$. As expected, contestants facing a stepwise increasing opt-out prize are more likely to opt out if there is more money on offer. We again find a ushaped relation with age: the estimates imply that the opt-out rate decreases with age if the contestant is younger than 46 years, and increases with age for older contestants. Education and type of decisive question are insignificant.

Model 2 exclusively considers mixed-gender cases, and confirms the descriptive result that women are significantly more likely to opt out than men in these situations. At any given moment, women are 85.3 percent more likely to opt out $(p=0.029)$. Model 3 exclusively considers single-gender pairs, and confirms that women facing a woman are not significantly more likely to opt out than men facing a man. In fact, the estimated hazard rate implies that women facing a woman are, at any given moment, 34.6 percent less likely to opt out than men facing a man. This difference, however, is statistically insignificant $(p=0.272)$.

\footnotetext{
${ }^{7}$ We exclude the second in which a contestant's opponent opted out, because it is unknown whether or not the contestant would otherwise have opted out herself in that second. Eight contestants are not included in the analysis, because their opponent opted out in the very first second. We find similar results if we include these seconds (assuming no opt out by the contestant).

${ }^{8}$ For variant $\mathrm{H} 1$ and $\mathrm{H} 2$ we set the value of the maximum opt-out prize variable to zero. The results do not depend on this choice, as long as the same value is applied for all $\mathrm{H} 1$ and $\mathrm{H} 2$ episodes.
} 


\section{Table 2: Regression results for game two}

The table displays hazard ratios from Cox proportional hazards model analyses of contestants' decisions to opt out (1) or not (0) in the second game. The estimation is stratified such that the baseline hazard is allowed to vary between the variant with an unknown prize and the variant with the money counter. Age is the contestant's age, measured in years and centered on the mean (46.4y). High educ. is a dummy variable that takes the value of 1 if the contestant has completed or is enrolled in higher education (bachelor's degree or higher), or has equivalent working experience. Opp. male is a dummy variable that takes the value of 1 if the opponent is male. Sum is a dummy variable that takes the value of 1 if the final question is a sum. Maximum prize (log) is the natural logarithm of the predetermined maximum opt-out cash prize in the $\mathrm{H} 3$ variant (and takes the value of zero for variants $\mathrm{H} 1$ and $\mathrm{H} 2$ ). Standard errors (in parentheses) are corrected for clustering at the episode level. Other definitions are as in Table 1.

\begin{tabular}{lccccc}
\hline & Model 1 & Model 2 & Model 3 & Model 4 & Model 5 \\
\hline Female & 1.126 & $1.853^{* *}$ & 0.654 & 1.049 & 1.109 \\
Age & $(0.226)$ & $(0.523)$ & $(0.253)$ & $(0.219)$ & $(0.426)$ \\
& 1.001 & 0.986 & 1.008 & 0.999 & 0.999 \\
Age ${ }^{2}$ / 100 & $(0.008)$ & $(0.012)$ & $(0.012)$ & $(0.008)$ & $(0.008)$ \\
& $1.145^{* * *}$ & $1.242^{* * *}$ & 1.039 & $1.163^{* * *}$ & $1.163^{* * *}$ \\
High educ. & $(0.046)$ & $(0.060)$ & $(0.108)$ & $(0.050)$ & $(0.050)$ \\
& 0.780 & $0.556^{*}$ & 0.708 & 0.736 & 0.734 \\
Opp. male & $(0.175)$ & $(0.187)$ & $(0.245)$ & $(0.170)$ & $(0.168)$ \\
& & & & $1.649 * *$ & $1.701^{* *}$ \\
Female x Opp. male & & & & $(0.343)$ & $(0.452)$ \\
& & & & 0.924 \\
Maximum prize (log) & $3.625^{* * *}$ & $2.784^{* *}$ & $5.273 * * *$ & $3.485^{* * *}$ & $(0.422)$ \\
& $(1.368)$ & $(1.282)$ & $(2.657)$ & $(1.298)$ & $\left(1.531^{* * *}\right.$ \\
Sum & 1.803 & 1.853 & 1.639 & 1.750 & 1.745 \\
& $(0.746)$ & $(0.939)$ & $(1.091)$ & $(0.720)$ & $(0.718)$ \\
\hline Data included & all & mixed-gender & single-gender & all & all \\
LL & -454.77 & -198.33 & -181.19 & -452.16 & -452.14 \\
Time at risk & 7,777 & 3,919 & 3,858 & 7,777 & 7,777 \\
No. of contestants & 358 & 181 & 177 & 358 & 358 \\
No. of opt-outs & 101 & 53 & 48 & 101 & 101 \\
No. of episodes & 183 & 93 & 90 & 183 & 183 \\
\hline
\end{tabular}

The results for Models 1, 2, and 3 suggest that in this strategic game men and women are roughly equally willing to compete (Models 1 and 3 ), but at the same time show that there is a large difference when they face an opponent of the opposite sex (Model 2). This combination of findings is consistent (i) with a lower propensity among women to compete against men than against women, as we also found for the first game, (ii) with a higher propensity among men to compete against women than against men, and (iii) with a combination of (i) and (ii).

To disentangle these three possible explanations, Models 4 and 5 use the data of all pairs of contestants. Model 4 includes a dummy variable that captures the gender of the opponent, and shows 
that contestants are 64.9 percent more likely to opt out when facing a man than when facing a woman $(p=0.016)$. Model 5 adds the interaction of the contestant's own gender and the opponent's gender, and indicates that there is no significant evidence that men and women respond differently to the gender of the opponent $(p=0.863)$.

In summary, the results for this game-where decisions are strategic in nature-suggest that men and women and equally willing to compete, and show that both genders avoid competing against a male opponent. A difference with the previous game is that earlier on many contestants were offered (and declined) one or more opportunities to opt out of the elimination competition. Consequently, it is likely that there was some degree of self-selection on competitiveness among the contestants that we observe. This could have lowered a possible general gender difference in competitiveness, but the results for the previous game show that such a gender difference neither occurs in the absence of such self-selection. It is unclear how self-selection could explain why both genders now avoid competing against men. Moreover, the game that we analyze in the Appendix has strategic interaction but no prior self-selection, and similarly yields evidence that both men and women avoid competing against men.

Combined, the analyses of the different games suggest that women have a particular dislike of competing against men, and that men are aware of this preference and exploit it in a strategic setting. There is little evidence for a general gender difference in the willingness to compete.

\section{Do the quiz questions favor men?}

A possible alternative explanation for some of the main results of our analyses is that women perform worse on the type of questions that are used in the elimination contest. If the questions favor men, it is rational for both men and women to respond to the gender composition of the competitor base, and to be more likely to opt out if the pool of competitors is more male-dominated. Such behavior is observed in the second game (and in the game in the Appendix), but not in the first game.

A priori, there is little reason to believe that there are material gender differences in performance among the contestants. First, the literature suggests that there are no gender differences in semantic memory (storing factual information) and in math ability, the two basic abilities that are fundamental to answering the type of questions in the elimination games (Herlitz, Nilsson and Bäckman, 1997; Nilsson, 2003; Hyde et al., 2008; Lindberg et al., 2010). Second, because most of the contestants in our analyses are from a high segment of the skill distribution, differences between contestants are likely to be relatively small. In the games that we study, almost all are people who made it up to that point 
because of exceptional performance on one or multiple questions. ${ }^{9}$ If there were any gender difference in skill among our audience members at all, it would be less pronounced among the select group of people that we observe in our games.

We can also use our data to explore whether men and women perform similar or not. In the stage-one game studied in Section 3, we can compare the gender of contestants who provided the best answer to one of the five questions - which are similar in nature to questions used in subsequent gameswith the gender of randomly selected contestants who were given a seat in the next stage if the winning contestant opted for an opt-out prize. In other words, we can consider whether the gender composition of successful contestants matches the gender composition of the population they are from. If one gender were better at the task, we would expect that gender to be overrepresented among the successful contestants. In total, there were 345 winners in the 69 episodes that featured this game. Among these winners there were 208 men (60.3\%). The number of contestants who received a seat in the next stage at random was 66 . Among these lucky contestants, 38 were male (57.6\%). The similarity of the two proportions suggests that the estimation questions did not particularly favor one of the two genders $\left(\operatorname{Chi}^{2}(1)=0.170, p=0.680\right)$.

We can also compare the overall performance of the two genders for game $G$ (see Figure 1). This game starts with five contestants and ends with two after three rounds of trivia quiz questions, with no possibility to opt out. The total pool of 345 contestants entering this game from game $F$ was composed of 219 (63.5\%) men and 126 (36.5\%) women. Out of the 138 survivors, 91 (65.9\%) were male and 47 (34.1\%) female. These statistics suggest that game $\mathrm{G}$ does not favor one gender: considered ex-post, the two genders had a similar chance of survival (men: $41.6 \%$, women: $37.3 \%$; $\operatorname{Chi}^{2}(1)=0.602$; $p=0.438) \cdot{ }^{10}$ Note, however, that most of the contestants in this comparison have chosen to continue the competition and enter this game when they were offered the possibility to opt out. If opting-out contestants were anticipating poor performance and those who continued believed they are good enough, the previous comparison might not capture the true gender difference in performance. Reassuringly, the same picture emerges when we exclusively focus on the 66 contestants who received

\footnotetext{
${ }^{9}$ In the first game, all gave a better response to an estimation question than nearly 500 competitors. In the second, all survived multiple elimination games (see Figure 1). In the game analyzed in the Appendix, five out of the six contestants were top performing contestants after three series of multiple choice questions (one was randomly selected; this person is the only exception).

${ }^{10}$ We obtain a similar result when we run a multivariate linear probability model where the dependent variable takes the value of one if the contestant survived (and zero otherwise), and where we include fixed effects for the contestant's seat number (lower numbers are more advantageous) and a quadratic specification for age. The coefficient for the contestant's gender in this regression is statistically insignificant $(p=0.372)$.
} 
their seat in this game at random and were not given the opportunity to opt out: 12 of the 38 men survive $(31.6 \%)$, and 8 of the 28 women $\left(28.6 \%\right.$; $\left.C h i^{2}(1)=0.069, p=0.793\right)$.

The notion that the quiz questions might favor men should be less of a concern for the game analyzed in the Appendix. Contestants gave their answer to the estimation question before they made the decision to opt out or not, and our regressions control for whether the contestant's answer ranked worst (which meant elimination if no one opted out). Moreover, our data does not yield compelling evidence of a gender difference in performance for this game. In the first round, where all 102 contestants answered the question, the frequencies by which men and women gave the worst answer are statistically indistinguishable (men: $19.2 \%$, women: $14.0 \%$; $\mathrm{Chi}^{2}(1)=0.502, p=0.479$ ). Combining all the data for this game in a regression-where we include fixed effects for the round number and a quadratic specification for age, and where we correct standard errors for clustering at the contestant and at the episode-round level-similarly yields no convincing evidence of a difference: women are 7.4 percentage points more likely to give the worst answer, but this effect is statistically insignificant $(p=0.108)$.

In the last game, the head-to-head game studied in Section 4, gender differences in ability are least likely to occur: those who made it to this stage have survived the previous stages of the elimination competition, and all can therefore be expected to be relatively strong. Still, we can empirically examine performance differences for the subset of 82 cases where neither of the two contestants opted out. This sample comprises 98 (59.8\%) men and 66 (40.2\%) women. Out of the 82 cases, 54 were decided through a sum and 28 through a multiple choice estimation question. We find no significant gender difference in performance among the contestants who pressed the button first and answered the decisive question, neither when we consider the sum nor when we consider the multiple choice estimation question: in the former case, 26 out of 34 men (76.5\%) and 13 out of 20 women (65.0\%) provide a correct answer $\left(\mathrm{Chi}^{2}(1)=0.826, p=0.363\right)$; in the latter case 3 out of 17 men $(17.7 \%)$ and 4 out of 11 women (36.4\%) provide a correct answer $\left(\mathrm{Chi}^{2}(1)=1.248, p=0.264\right)$. Furthermore, we can use the mixed-gender pairs to explore whether men and women differ in their propensity to press the button and answer the question. Any such difference could reflect a gender difference in competitiveness, but also a gender difference in the ability to give the correct answer. The data, however, suggest that men and women are roughly equally likely to press the button. Out of the 26 mixed-gender cases where the final question is a sum, the man (woman) presses the button 14 (12) times (men: 53.8\%, women: 46.2\%; $\operatorname{Ch}^{2}(1)=0.308, p=0.579$ ). Out of the 14 mixed-gender cases with a multiple choice question, the man (woman) is the first to press the button 8 (6) times (men: $57.1 \%$, women: $42.9 \%$; $\left.C h i^{2}(1)=0.571, p=0.450\right)$. 
In conclusion, our data provide no compelling evidence that men and women perform differently on the tasks that are central in the elimination competition. Taken together, it is unlikely that the results in the previous sections can somehow be explained by differences in the ability of men and women to answer the questions.

\section{Conclusion and discussion}

The present paper examined gender differences in willingness to compete for high stakes, using a TV game show where the winner of an elimination competition plays a game of chance worth hundreds of thousands of euros. The amounts that are at stake in this real-life setting are much closer to the sums involved in promotion competitions at the top of the labor market than the financial rewards that are commonly employed in laboratory experiments.

We focused on two different games. In the first, contestants choose between competing in the next elimination game and opting out for a prize. This decision resembles the tournament-entry decision that subjects typically make in lab experiments. In line with the picture that emerges from the experimental literature, we find that women are twice as likely as men to avoid the competition. The comparatively high opt-out rate of women, however, derives entirely from situations where they will face predominantly male opponents. This suggests that women have a particular dislike of competing against men, rather than a more general dislike of competition. In this non-strategic game, men do not appear to condition their behavior on the gender of their opponents.

In the second game one question determines the last elimination, unless one of the two remaining contestants voluntarily accepts an opt-out prize. This head-to-head game is relatively complex, because the optimal choice depends on the anticipated behavior of the opponent. The results show that both genders avoid competing against a male opponent in this strategic setting. The same pattern arises in the strategic game analyzed in the Appendix. This pattern confirms the result for the first game that women avoid competing against men, and suggests that in strategic interactions men anticipate a lower willingness to compete among their female opponents. In line with the results for the first game, there is no evidence of a main effect of gender on competitiveness.

Altogether, the results confirm that gender differences in willingness to compete also occur in situations where the stakes are very high, but they also indicate that the stereotypical image and widely-held belief that women are less competitive than men is too simplistic. The findings show the importance of the gender of competitors and of the presence of strategic interaction: women appear to dislike competing against men, and men appear to exploit this when there is strategic interaction. 
Hitherto, the literature on gender differences in willingness to compete has largely ignored these two factors. Exceptions are Booth and Nolen (2012) and Geraldes (2018), who similarly find that women avoid competing against men. Such a dislike is in line with evidence that women perform worse when they compete against men (Gneezy, Niederle and Rustichini, 2003; Günther et al., 2010; Backus et al., 2016; de Sousa and Hollard, 2016; Booth, Cardona-Sosa and Nolen, 2018; Booth and Yamamura, 2018). Strategic interaction is typically ruled out by design in willingness-to-compete experiments.

Research somewhat removed from the willingness-to-compete literature indirectly supports our conclusion about the importance of opponent gender in strategic interactions. Babcock et al. (2017) show that women are more likely than men to volunteer for an undesirable task when interacting in mixed-gender groups, but not when interacting in single-gender groups. Booth and Yamamura (2018) study Japanese speedboat races and find that men adopt a more aggressive racing style in mixedgender races than in single-gender races, whereas women act less aggressively in mixed-gender races than in single-gender races. Hernandez-Arenaz and Iriberri (2018) investigate bargaining behavior in a Spanish TV game show and find that women ask less from men than from women.

Our setting differs in a number of ways from that of a traditional laboratory experiment. In addition to the markedly higher stakes, the subject pool that we observe is much more diverse, and because of the presence of a large audience and cameras, our contestants' decisions are observed by many and subject to considerable public scrutiny. A benefit of the diverse pool of contestants is that we can also explore how competitiveness varies with age. We consistently find a u-shaped relation, with people who are in their forties displaying the lowest opt-out propensity. Mayr et al. (2012) find a similar relation between age and competitiveness among subjects in an incentivized experiment. Flory et al. (2018) and Buser, Niederle and Oosterbeek (2020), however, report different age patterns.

A benefit of the public nature of the competition, is that this feature is shared by many consequential real world competitions. In the political arena and upper echelons of the corporate world, for example, people face considerable public scrutiny when they compete for top positions. This is another argument for why our naturally occurring setting is much more similar to such real-world situations than anonymous, low-stakes laboratory experiments. Because opting out of the competition ends public observability and choosing to compete extends it, a difference in the attitudes of men and women towards public observability would obfuscate the relation between gender and competitiveness. To the best of our knowledge, the only paper that studies the impact of public observability on competitiveness is Buser, Ranehill and van Veldhuizen (2019). They find suggestive evidence that public observability increases men's willingness to compete, but conclude that public observability does not alter the magnitude of the gender gap in willingness to compete in an 
economically or statistically significant way. This possible confound also occurs in many real-life settings, but cannot explain why women display a dislike of competing against men and why men are more competitive when they face women in a strategic setting.

Similar to the tasks that are typically used in willingness-to-compete experiments, the questions that are central in the elimination competition are often numerical or arithmetic in nature. This similarity facilitates the comparison of our results with those of previous studies. Research on competitiveness often intentionally uses such tasks because mathematics is a stereotypically male area, which brings the research closer to competitive situations in male-dominated workplaces or male-connotated areas such as management (Niederle and Vesterlund, 2011). Although we cannot entirely rule out that our results are partly driven by a gender difference in the ability to answer the questions, none of the additional analyses of our data provide evidence that the quiz questions actually favor men. Second, based on research into math performance and research into recall of factual information, there is little reason to believe that such a difference holds true for the general population (Herlitz et al., 1997; Nilsson, 2003; Hyde et al., 2008; Lindberg et al., 2010). Last, even if any gender difference would exist among the initial pool of contestants, it would be relatively small among those we study because weaker contestants are less likely to reach the stages of interest.

Of course, contestants may have held non-rational expectations about their own ability and that of others, possibly inspired by stereotypical beliefs about the performance of men and women on math questions. Indeed, in experimental work that uses a neutral or stereotypically female type of task, competitiveness differences between men and women are sometimes, but not always, weak or absent (Große and Riener, 2010; Shurchkov, 2012; Dreber, von Essen and Ranehill, 2014; Wozniak, Harbaugh and Mayr, 2014). Stereotype-biased beliefs about performance may explain why women display a relatively low propensity to compete against men in all the games that we study, and why men display a relatively high propensity to compete against women when the game is strategic. This explanation, however, is not supported by the behavior of men in the first game: there is no evidence that men are especially eager to compete against women. If anything, men are more likely to opt out against women than against men in this game.

A possible concern about our findings is that their generalizability might be negatively affected by selection effects. Selection procedures are inevitable in any lab experiment or field setting, and could potentially bias comparisons of the behavior of men and women (Larkin and Pines, 2003; Reback and Stowe, 2011; Hogarth, Karelaia and Trujillo, 2012). Unlike contestants in most other game shows, however, contestants in our elimination competition do not need to self-select into auditions and are not screened and then selected by producers prior to their participation. All have won their ticket 
through the popular Dutch Postcode Lottery. Even for competition-averse individuals, using this ticket is attractive: in addition to the lucrative possibility of becoming the finalist, contestants can win many other large prizes. Nevertheless, subjects in our study are not selected perfectly at random: all are lottery players who were able to attend the recording, and couples might send the best or most competitive of the two of them. Still, as a group the subjects in our study do resemble a cross-section of the general population much more closely than subjects in most lab experiments and other field studies do. More importantly, it is not clear how selection mechanisms could explain that the competitiveness of men and women depends on the gender of their opponent.

Our study finds that women avoid competition against men, but remains silent on the underlying causes of this behavior. According to the literature, differences in reluctance to compete can be driven by differences in risk attitudes, (over)confidence, and intrinsic attitudes towards competition. However, even in controlled experiments, and even without strategic interaction and consideration of the role of the gender of opponents, careful disentangling of the possible determinants of competitiveness has proven to be methodologically challenging (van Veldhuizen, 2018; Gillen, Snowberg and Yariv, 2019). Our field data is not rich enough for delving into the possible explanations, but it seems implausible that risk preferences depend on the gender of the opponents. This leaves opponent-dependent confidence in performance and intrinsic opponent-dependent attitudes towards competition as the most likely drivers: women could be less confident about their performance in a competition against men, or have a more deeply rooted, intrinsic aversion to competing against men. Such a specific response to the opponent's gender can, in turn, be partly determined by the culture in which people grow up (Gneezy, Leonard and List, 2009; Andersen et al., 2013; Booth et al., 2019; Zhang, 2019).

Research into the effect of social class and ethnicity on competitiveness suggest that gender differences in competitiveness-including those identified in the present study-may derive from a more general phenomenon, where willingness to compete relates to social power and status. Almås et al. (2016b) find that gender differences in competitiveness arise between boys and girls from families with a high socioeconomic status only, and not between those who are from families with a low socioeconomic status. Siddique and Vlassopoulos (2019) report that people from an ethnic minority group are more likely to compete when their competitors are all co-ethnic than when their competitors are predominantly from the majority group.

Regardless of the possible psychological mechanisms, the finding that women avoid competing against men has the important implication that male dominance in a professional environment becomes selfperpetuating. This is especially the case if there is strategic interaction, where those who compete are 
better off when others abstain from competing. In such a setting, women can expect more pushback from both male and female competitors. At the higher rungs of the career ladder, where overrepresentation of men and strategic interaction are both ubiquitous, affirmative action may be necessary to alter the status quo.

\section{Appendix: Game D1 (from 6 to 2)}

\section{Description and data}

In the period from November 2006 until December 2007, the elimination competition featured a game that reduced the number of contestants from six to two in four rounds. In each round, the remaining contestants were given an estimation question. Examples are "How many pieces does the largest jigsaw puzzle sold in ordinary stores contain?" and "How many items of clothing does a woman on average have in her wardrobe, according to onepoll.com?". All contestants had to privately give their best guess by entering it into their terminal, and the correct answer was then publicly revealed. Prior to the identification of the player with the worst guess, contestants were given the opportunity to voluntarily leave the game in exchange for a monetary opt-out prize. In contrast to the second game analyzed in the main text, where contestants who want to opt out can wait for an unknown but considerable amount of time in the hope that the other opts out, contestants in the present game need to do so almost instantly. The total opt-out prize money available for the four rounds was always $€ 40,000$ per episode, divided unequally across four sealed briefcases. Opting-out contestants were rewarded with the contents of one of these cases, selected by themselves. Only one contestant, the fastest, could opt out. If no contestant opted out, the player with the worst guess was sent home empty-handed. The six contestants who played this game were selected from the larger crowd through a series of multiple-choice questions, game $\mathrm{A} 2$ in Figure 1 . This preceding game did not have any optout options, consequently no self-selection on competitiveness occurred yet.

We collected the data for all 17 episodes that featured this elimination game. The overall gender distribution at the start was balanced, with 50 of the total of $102(49.0 \%)$ contestants being male. The average age was 48 years (min: 23 , max: 83 ). In 41 of the total of 68 rounds (60.3\%) one of the contestants opted out. Contestants who opted out had given the worst answer 61.0 percent of the times, and, with hindsight, opting out was therefore the optimal decision for them. In the other 27 rounds (39.7\%) no one opted out, and consequently the contestant with the worst answer was automatically eliminated. The expected value of the remaining opt-out prizes at the time the opt-out decisions were made varied between $€ 4,000$ and $€ 16,000$. 

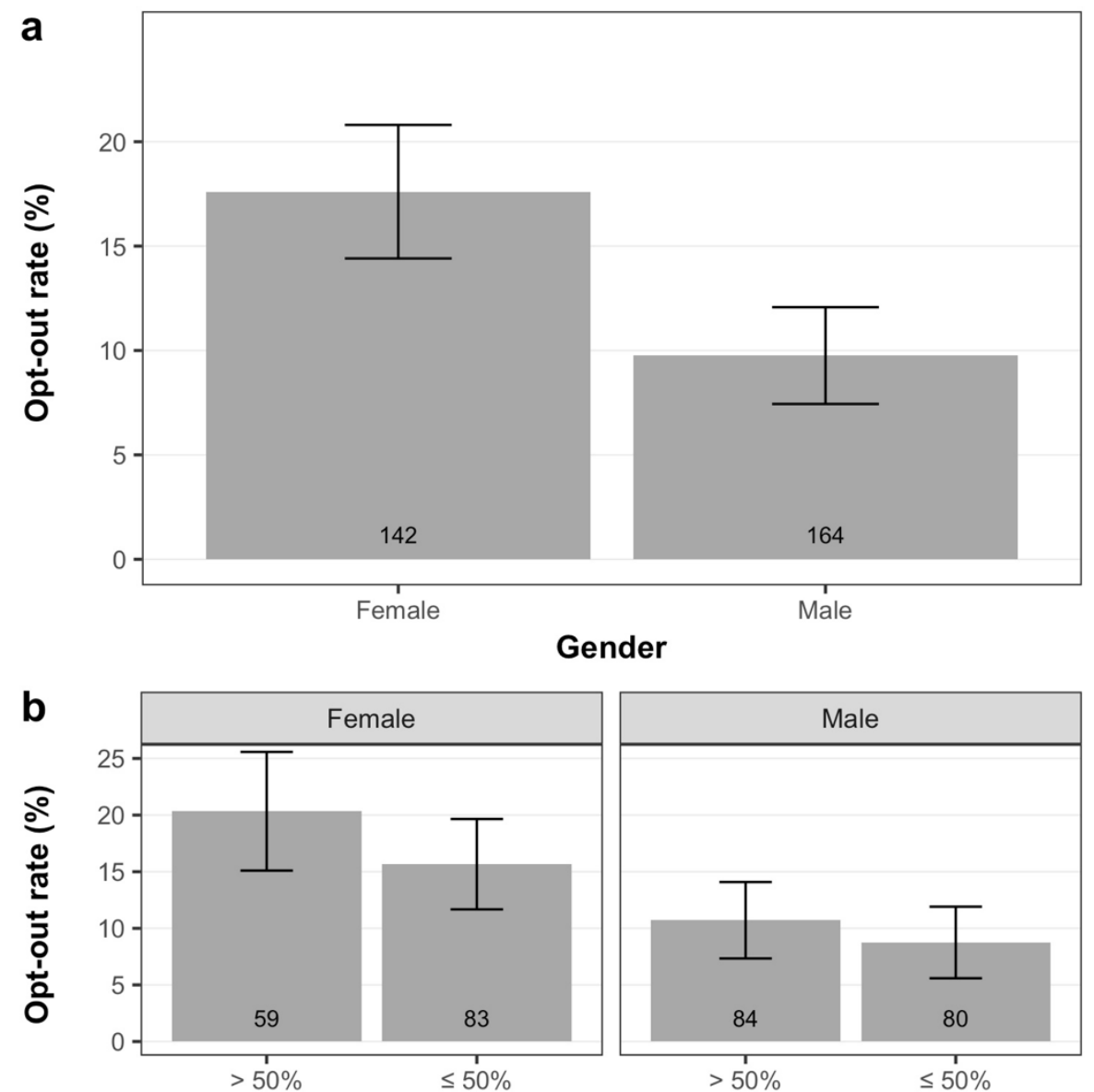

Prop. opp. male

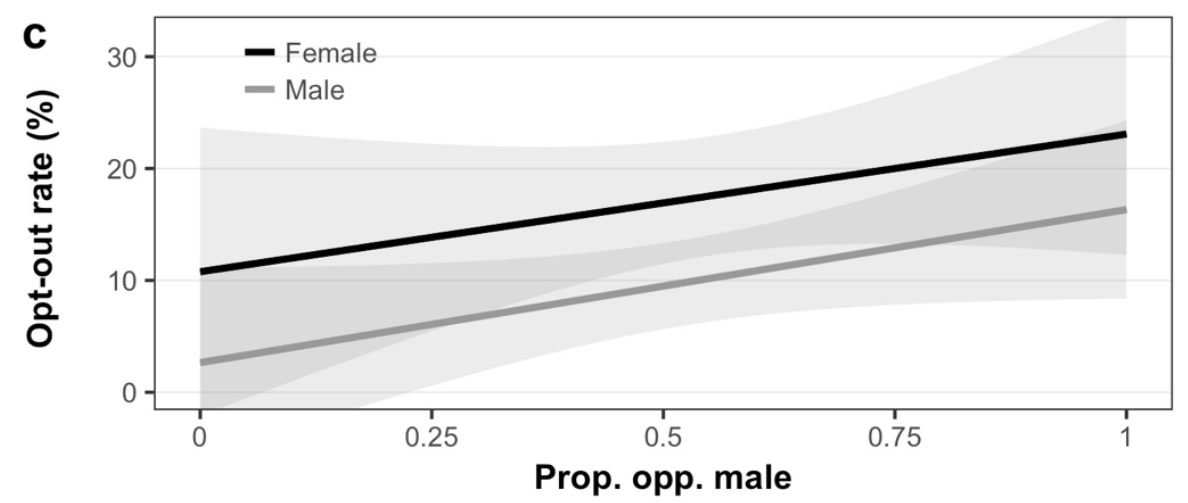

Figure A1: Opt-out rates for men and women in game D1. (a) displays the opt-out rates for male and female contestants. (b) displays the opt-out rates for male and female contestants, conditional on whether more than half of the remaining opponents are male ( $>50 \%$ opponents male), and conditional on whether half or more of the remaining opponents are female $(\leq 50 \%$ opponents male). The number of observations is at the bottom of each bar. Error bars depict standard errors around the mean. (c) displays the univariate linear relationship between the opt-out rate and the proportion of male opponents, for male and female contestants separately. The shaded areas represent $90 \%$ confidence intervals. 


\section{Analyses and results}

Across all rounds combined, the opt-out rate is 13.4 percent. ${ }^{11}$ As illustrated in Figure A1a, women are about twice as likely to opt out as men (males: 9.8\%, females: $17.6 \% ; \mathrm{Chi}^{2}(1)=4.041, p=0.044$ ).

We estimate a multivariate linear probability model to control for differences in contestants' age, the expected value of taking an opt-out prize, and round-number fixed effects. Again, the dependent variable takes the value of one if the contestant opts out (and zero otherwise). As in the analyses of the other games, we use a quadratic specification for age. In addition, we include round-number fixed effects. Controlling for round number is important, because the possible range of the opt-out rate differs across rounds: in the first round no more than one in six contestants can opt out, whereas in the last round no more than one in three can opt out. We correct the standard errors for clustering at the contestant level and at the episode-round level (Cameron, Gelbach and Miller, 2011; Thompson, 2011).

Table A1, Model 1 presents the results. Controlling for age, expected value of opting out, and round number, women are 9.4 percentage points more likely to opt out than men. Similar to stage one, we find a u-shaped relation between the opt-out rate and age (the coefficients imply that the rate is lowest at 41 years). Furthermore, contestants do not appear very concerned with the expected value of the cash opt-out prize.

Model 2 includes a dummy variable that takes the value of one if a contestant provided the worst guess in that round, and zero otherwise. When contestants make up their mind about whether they should opt out or not, they probably factor in their subjective impression of the likelihood that they are the one who has given the worst answer to the estimation question. Contestants know both their own guess and the correct answer, but they do not know the guesses that the others have entered and how likely these others are to give up. The dummy variable is a strong predictor: contestants who provided the worst guess are 28.7 percentage points more likely to opt out than those who did not provide the worst guess, and incorporating this variable increases the $R^{2}$ from 0.053 to 0.173 . Importantly, the effect of gender is robust to including the worst-guess variable. As compared to Model 1 , the coefficient of the gender variable decreases from $9.4 \%$ to $7.2 \%$, which can be attributed to women's slightly worse-but statistically not significantly worse-performance in this task (see Section 5).

\footnotetext{
${ }^{11}$ The highest possible opt-out rate is 16.7 percent in round one ( 1 out of 6 contestants can opt out), 20.0 percent in round two ( 1 out of 5), 25.0 percent in round three ( 1 out of 4), and 33.3 percent in round four ( 1 out of 3 ). Across all choices combined, the opt-out rate cannot be higher than 22.2 percent.
} 
Table A1: Regression results for game D1

The table displays results from regression analyses of contestants' decisions to opt out (1) or not (0) in game D1. Age is the contestant's age, measured in years and centered on the mean (46.9y). Prop. opp. male is the proportion of male opponents, centered on the mean (0.54). Worst guess is a dummy variable that takes the value of 1 if the contestant provided the worst guess in the given round. EV opt out is the expected value of opting out in euros. All models include round-number fixed effects. Standard errors (in parentheses) are corrected for clustering at the contestant level and at the episode-round level. Other definitions are as in Table 1.

\begin{tabular}{|c|c|c|c|c|c|c|}
\hline & Model 1 & Model 2 & Model 3 & Model 4 & Model 5 & Model 6 \\
\hline \multirow[t]{2}{*}{ Female } & $0.094^{* *}$ & $0.072^{* *}$ & $0.076^{* *}$ & 0.073 & $0.068^{*}$ & $0.068^{*}$ \\
\hline & $(0.039)$ & $(0.036)$ & $(0.038)$ & $(0.046)$ & $(0.036)$ & $(0.036)$ \\
\hline \multirow[t]{2}{*}{ Age } & 0.003 & $0.003^{*}$ & $0.003^{*}$ & $0.003^{*}$ & 0.003 & 0.003 \\
\hline & $(0.002)$ & $(0.002)$ & $(0.002)$ & $(0.002)$ & $(0.002)$ & $(0.002)$ \\
\hline \multirow{2}{*}{$\mathrm{Age}^{2} / 100$} & $0.029 *$ & $0.028 *$ & $0.029 * *$ & $0.029 * *$ & $0.031 * *$ & $0.031^{* *}$ \\
\hline & $(0.017)$ & $(0.014)$ & $(0.014)$ & $(0.014)$ & $(0.014)$ & $(0.014)$ \\
\hline \multirow[t]{2}{*}{ Majority opp. male $(>50 \%$ male $=1)$} & & & 0.038 & 0.035 & & \\
\hline & & & $(0.032)$ & $(0.044)$ & & \\
\hline Gender x Majority opp. male & & & & $\begin{array}{c}0.007 \\
(0.075)\end{array}$ & & \\
\hline \multirow[t]{2}{*}{ Prop. opp. male } & & & & & $0.126^{* *}$ & $0.139 *$ \\
\hline & & & & & (0.059) & $(0.073)$ \\
\hline \multirow[t]{2}{*}{ Gender x Prop. opp. male } & & & & & & -0.030 \\
\hline & & & & & & $(0.135)$ \\
\hline \multirow{2}{*}{ Worst guess $($ worst $=1$ ) } & & $0.287^{* * *}$ & $0.287 * * *$ & $0.287^{* * *}$ & $0.284^{* * *}$ & $0.284^{* * *}$ \\
\hline & & $(0.061)$ & $(0.062)$ & $(0.062)$ & $(0.062)$ & $(0.062)$ \\
\hline \multirow[t]{2}{*}{ EV opt out / 1000} & 0.008 & 0.008 & 0.009 & 0.009 & 0.009 & 0.009 \\
\hline & $(0.010)$ & $(0.010)$ & $(0.009)$ & $(0.009)$ & $(0.009)$ & $(0.009)$ \\
\hline Round-number fixed effects & yes & yes & yes & yes & yes & yes \\
\hline$R^{2}$ & 0.053 & 0.173 & 0.176 & 0.176 & 0.182 & 0.182 \\
\hline No. of observations & 306 & 306 & 306 & 306 & 306 & 306 \\
\hline No. of contestants & 102 & 102 & 102 & 102 & 102 & 102 \\
\hline No. of rounds & 68 & 68 & 68 & 68 & 68 & 68 \\
\hline No. of episodes & 17 & 17 & 17 & 17 & 17 & 17 \\
\hline
\end{tabular}

Given the strategic nature of this game-if someone opts out, the rest are safe-contestants should condition their choices on the likelihood that one of their opponents will opt out. If contestants' beliefs are based on the stereotypical view that women are less competitive than men, then both men and women will be more likely to compete against women than they will be against men. The same prediction follows from a dislike among women to compete against men-as we observed in the first game-and men being aware of women's reluctance to compete against them.

Figure A1b shows the opt-out rates of men and women, and distinguishes between situations where more than half of the opponents are male and situations where half or more are female. Both men and women are somewhat more likely to opt out when most of their opponents are male as compared to situations where half or more of their opponents are female, but statistically the two differences 
are insignificant (women: $20.3 \%$ vs. $15.7 \% ; \operatorname{Chi}^{2}(1)=0.520, p=0.471 ;$ men: $10.7 \%$ vs. $8.8 \%$, $\left.\operatorname{Chi}^{2}(1)=0.180, p=0.672\right)$. In Table A1, Model 3 incorporates the binary distinction between male and female dominated competition in the regression analysis through the inclusion of a dummy variable that takes the value of one if more than half of the opponents is male (and zero otherwise), and shows that there is no significant effect of this dummy variable on the opt-out rates of men and women combined $(p=0.228)$. Model 4 adds the interaction of the dummy variable with the contestant's own gender, and shows that the effect of the dummy variable does not differ significantly between men and women $(p=0.927)$.

The binary distinction is rather crude, which likely limited the statistical power. We therefore repeat the analyses with the exact (demeaned) proportion of male opponents. Figure A1c shows the linearly fitted relationship between the opt-out rate and this continuous measure, for male and female contestants separately. The graph suggests that both men and women are more likely to opt out when the proportion of male opponents is higher. In Table A1, Model 5 includes this proportion in the regression analysis, and confirms that opt-out rates vary significantly with the gender of opponents: contestants are 12.6 percentage points more likely to opt out if they exclusively face male competitors, as compared to the situation where they exclusively face female competitors ( $p=0.034)$. Model 6 adds the interaction of the proportion of male opponents and the contestant's own gender. The results suggest that men and women respond similarly to the gender composition $(p=0.823)$. The stand-alone effect of contestants' gender is now marginally significant: women are 6.8 percentage points more likely to opt out than men (both $p<0.059$ ).

In summary, in this game, where beliefs about the competitive behavior of others matter for the decision to opt out, we observe that women are marginally significantly more likely than men to be the one who opts out, and that both men and women opt out more often when the proportion of male opponents is larger. These results, however, have to be interpreted with caution. If one contestant opts out, it remains unknown what the other contestants would have done. As a consequence of this censoring problem, the opt-out choices that we observe for individual contestants do not only depend on individuals' own opt-out propensity, but also on those of their opponents. The relatively high optout rate among women, for example, can reflect a higher general opt-out propensity, which would be at odds with the finding in the previous game that women exclusively dislike competing against men. At the same time, it can also derive from censoring: if opponents are less likely to opt out when facing a woman than when facing a man, then a female contestant with a given propensity to opt-out will more often be the one who actually opts out than a male contestant with the exact same propensity, simply because less often someone else has already opted out. 
Notwithstanding this caveat, the results for this game point out that men are better off than women in a setting where people who choose to compete have higher chances to be successful if others abstain from competing.

\section{References}

Almås, Ingvild, Alexander W. Cappelen, Kjell G. Salvanes, Erik $\varnothing$. Sørensen, and Bertil Tungodden. 2016a. "What Explains the Gender Gap in College Track Dropout? Experimental and Administrative Evidence." American Economic Review 106(5): 296-302.

Almås, Ingvild, Alexander W. Cappelen, Kjell G. Salvanes, Erik $\varnothing$. Sørensen, and Bertil Tungodden. 2016b. “Willingness to Compete: Family Matters." Management Science 62(8): 2149-2162.

Andersen, Steffen, Seda Ertac, Uri Gneezy, John A. List, and Sandra Maximiano. 2013. "Gender, Competitiveness, and Socialization at a Young Age: Evidence from a Matrilineal and a Patriarchal Society." Review of Economics and Statistics 95(4): 1438-1443.

Antonovics, Kate, Peter Arcidiacono, and Randall Walsh. 2005. "Games and Discrimination: Lessons from 'The Weakest Link'." Journal of Human Resources 40(4): 918-947.

Babcock, Linda, Maria P. Recalde, Lise Vesterlund, and Laurie Weingart. 2017. "Gender Differences in Accepting and Receiving Requests for Tasks with Low Promotability." American Economic Review 107(3): 714-47.

Backus, Peter, Maria Cubel, Matej Guid, Santiago Sánchez-Pagés, and Enrique Lopez Manas. 2016. "Gender, Competition and Performance: Evidence from Real Tournaments." Working paper.

Belot, Michèle, V. Bhaskar, and Jeroen van de Ven. 2012. "Beauty and the Sources of Discrimination." Journal of Human Resources 47(3): 851-872.

Bennett, Randall W., and Kent A. Hickman. 1993. "Rationality and the 'Price is Right'." Journal of Economic Behavior \& Organization 21(1): 99-105.

Berge, Lars Ivar Oppedal, Kjetil Bjorvatn, Armando Jose Garcia Pires, and Bertil Tungodden. 2015. "Competitive in the Lab, Successful in the Field?" Journal of Economic Behavior \& Organization 118: 303-317.

Berk, Jonathan B., Eric Hughson, and Kirk Vandezande. 1996. "The Price Is Right, But Are the Bids? An Investigation of Rational Decision Theory." American Economic Review 86(4): 954-970.

Blau, Francine D., and Lawrence M. Kahn. 2017. "The Gender Wage Gap: Extent, Trends, and Explanations." Journal of Economic Literature 55(3): 789-865. 
Blavatskyy, Pavlo, and Ganna Pogrebna. 2010. "Models of Stochastic Choice and Decision Theories: Why Both Are Important for Analyzing Decisions." Journal of Applied Econometrics 25(6): 963986.

Bombardini, Matilde, and Francesco Trebbi. 2012. "Risk Aversion and Expected Utility Theory: An Experiment with Large and Small Stakes." Journal of the European Economic Association 10(6): 1348-1399.

Booth, Alison L., Lina Cardona-Sosa, and Patrick Nolen. 2018. "Do Single-Sex Classes Affect Academic Achievement? An Experiment in a Coeducational University." Journal of Public Economics 168: 109-126.

Booth, Alison L., Elliott Fan, Xin Meng, and Dandan Zhang. 2019. “Gender Differences in Willingness to Compete: The Role of Culture and Institutions." Economic Journal 129(618): 734-764.

Booth, Alison L., and Patrick Nolen. 2012. "Choosing to Compete: How Different Are Girls and Boys?” Journal of Economic Behavior \& Organization 81(2): 542-55.

Booth, Alison, and Eiji Yamamura. 2018 "Performance in Mixed-Sex and Single-Sex Competitions: What We Can Learn from Speedboat Races in Japan." Review of Economics and Statistics 100(4): 581593.

Brooks, Robert D., Robert W. Faff, Daniel Mulino, and Richard Scheelings. 2009. “Deal or No Deal, That Is the Question: The Impact of Increasing Stakes and Framing Effects on Decision-Making under Risk." International Review of Finance 9(1-2): 27-50.

Buser, Thomas, Lydia Geijtenbeek, and Erik Plug. 2018. "Sexual Orientation, Competitiveness and Income." Journal of Economic Behavior \& Organization 151: 191-198.

Buser, Thomas, Muriel Niederle, and Hessel Oosterbeek. 2014. "Gender, Competitiveness, and Career Choices." Quarterly Journal of Economics 129(3): 1409-1447.

Buser, Thomas, Muriel Niederle, and Hessel Oosterbeek. 2020. "Can Competitiveness Predict Education and Labor Market Outcomes? Evidence from Incentivized Choice and Survey Measures." Working paper.

Buser, Thomas, Noemi Peter, and Stefan C. Wolter. 2017a. "Gender, Competitiveness, and Study Choices in High School: Evidence from Switzerland." American Economic Review 107(5): 125130.

Buser, Thomas, Noemi Peter, and Stefan C. Wolter. 2017b. "Gender, Willingness to Compete and Career Choices Along the Whole Ability Distribution." Working paper.

Buser, Thomas, Eva Ranehill, and Roel van Veldhuizen. 2019. "Gender Differences in Willingness to Compete: The Role of Public Observability." Working paper.

Cameron, A. Colin, Jonah B. Gelbach, and Douglas L. Miller. 2011. "Robust Inference with Multiway Clustering." Journal of Business \& Economic Statistics 29(2): 238-249. 
Cox, David R. 1972. "Regression Models and Life-Tables." Journal of the Royal Statistical Society: Series $B$ (Methodological) 34(2): 187-220.

Croson, Rachel, and Uri Gneezy. 2009. "Gender Differences in Preferences." Journal of Economic Literature 47(2): 448-474.

Datta Gupta, Nabanita, Anders Poulsen, and Marie Claire Villeval. 2013. "Gender Matching and Competitiveness: Experimental Evidence." Economic Inquiry 51(1): 816-835.

de Roos, Nicolas, and Yianis Sarafidis. 2010. "Decision Making under Risk in Deal or No Deal." Journal of Applied Econometrics 25(6): 987-1027.

de Sousa, José, and Guillaume Hollard. 2016. "Gender Differences: Evidence from Field Tournaments." Working paper.

Deck, Cary A., Jungmin Lee, and Javier A. Reyes. 2008. "Risk Attitudes in Large Stake Gambles: Evidence from a Game Show." Applied Economics 40(1): 41-52.

Dreber, Anna, Emma von Essen, and Eva Ranehill. 2014. "Gender and Competition in Adolescence: Task Matters." Experimental Economics 17(1): 154-172.

Flory, Jeffrey A., Uri Gneezy, Kenneth L. Leonard, and John A. List. 2018 “Gender, Age, and Competition: A Disappearing Gap?" Journal of Economic Behavior \& Organization 150: 256-276.

Flory, Jeffrey A., Andreas Leibbrandt, and John A. List. 2015. “Do Competitive Workplaces Deter Female Workers? A Large-Scale Natural Field Experiment on Job Entry Decisions." Review of Economic Studies 82(1): 122-155.

Geraldes, Diogo. 2018. “Women Dislike Competing Against Men." Working paper.

Gertner, Robert. 1993. “Game Shows and Economic Behavior: Risk-Taking on 'Card Sharks'.” Quarterly Journal of Economics 108(2): 507-521.

Gillen, Ben, Erik Snowberg, and Leeat Yariv. 2019. "Experimenting with Measurement Error: Techniques with Applications to the Caltech Cohort Study." Journal of Political Economy 127(4): 1826-1863.

Gneezy, Uri, Kenneth L. Leonard, and John A. List. 2009. “Gender Differences in Competition: Evidence from a Matrilineal and a Patriarchal Society." Econometrica 77(5): 1637-1664.

Gneezy, Uri, Muriel Niederle, and Aldo Rustichini. 2003. "Performance in Competitive Environments: Gender Differences." Quarterly Journal of Economics 118(3): 1049-1074.

Große, Niels D. and Gerhard Riener. 2010. “Explaining Gender Differences in Competitiveness: GenderTask Stereotypes." Working paper.

Günther, Christina, Neslihan Arslan Ekinci, Christiane Schwieren, and Martin Strobel. 2010. "Women Can't Jump? An Experiment on Competitive Attitudes and Stereotype Threat." Journal of Economic Behavior \& Organization 75(3): 395-401. 
Herlitz, Agneta, Lars-Göran Nilsson, and Lars Bäckman. 1997. "Gender Differences in Episodic Memory." Memory \& Cognition 25(6): 801-811.

Hernandez-Arenaz, Iñigo, and Nagore Iriberri. 2018. "Women Ask for Less (Only from Men): Evidence from Bargaining in the Field." Journal of Economic Behavior \& Organization 152: 192-214.

Hogarth, Robin M., Natalia Karelaia, and Carlos Andrés Trujillo. 2012. "When Should I Quit? Gender Differences in Exiting Competitions." Journal of Economic Behavior \& Organization 83(1): 136150.

Hyde, Janet S., Sara M. Lindberg, Marcia C. Linn, Amy B. Ellis and Caroline C. Williams. 2008. "Gender Similarities Characterize Math Performance." Science 321(5888): 494-495.

Larkin, Judith E., and Harvey A. Pines. 2003. "Gender and Risk in Public Performance." Sex Roles 49(5/6): 197-210.

Levitt, Steven D. 2004. "Testing Theories of Discrimination: Evidence from Weakest Link." Journal of Law and Economics 47(2): 431-453.

Lindberg, Sara M., Janet S. Hyde, Jennifer S. Petersen, and Marcia C. Linn. 2010. “New Trends in Gender and Mathematics Performance: A Meta-Analysis." Psychological Bulletin 136(6): 1123-1135.

List, John A. 2006. "Friend or Foe? A Natural Experiment of the Prisoner's Dilemma." Review of Economics and Statistics 88(3): 463-471.

Mayr, Ulrich, Dave Wozniak, Casey Davidson, David Kuhns, and William T. Harbaugh. 2012. "Competitiveness across the Life Span: The Feisty Fifties." Psychology and Aging 27(2): 278-285.

Metrick, Andrew. 1995. "A Natural Experiment in 'Jeopardy'." American Economic Review 85(1): 240253.

Niederle, Muriel, and Lise Vesterlund. 2007. "Do Women Shy Away From Competition? Do Men Compete Too Much?" Quarterly Journal of Economics 122(3): 1067-1101.

Niederle, Muriel, and Lise Vesterlund. 2011. "Gender and Competition." Annual Review of Economics 3: 601-630.

Nilsson, Lars-Göran. 2003. "Memory Function in Normal Aging." Acta Neurologica Scandinavica 107(Suppl. 179): 7-13.

Oberholzer-Gee, Felix, Joel Waldfogel, and Matthew W. White. 2010. “Friend or Foe? Cooperation and Learning in High-Stakes Games." Review of Economics and Statistics 92(1): 179-187.

Post, Thierry, Martijn J. van den Assem, Guido Baltussen, and Richard H. Thaler. 2008. "Deal or No Deal? Decision Making under Risk in a Large-Payoff Game Show." American Economic Review 98(1): 38-71.

Reback, Charles, and Kristin Stowe. 2011. "Unnatural Experiments: The Case of Television Game Shows." Applied Economics Letters 18(10): 919-923. 
Reuben, Ernesto, Paola Sapienza, and Luigi Zingales. 2019. “Taste for Competition and the Gender Gap Among Young Business Professionals". Working paper.

Samek, Anya. 2019. "Gender Differences in Job Entry Decisions: A University-Wide Field Experiment." Management Science 65(7): 2947-3448.

Shurchkov, Olga. 2012. "Under Pressure: Gender Differences in Output Quality and Quantity under Competition and Time Constraints." Journal of the European Economic Association 10(5): 11891213.

Siddique, Abu, and Michael Vlassopoulos. 2019. "Competitive Preferences and Ethnicity: Experimental Evidence from Bangladesh." Economic Journal, forthcoming.

Tenorio, Rafael, and Timothy N. Cason. 2002. "To Spin or Not To Spin? Natural and Laboratory Experiments from 'The Price Is Right'." Economic Journal 112(476): 170-195.

Thompson, Samuel B. 2011. "Simple Formulas for Standard Errors That Cluster by Both Firm and Time." Journal of Financial Economics 99(1), 1-10.

Turmunkh, Uyanga, Martijn J. van den Assem, and Dennie van Dolder. 2019. "Malleable Lies: Communication and Cooperation in a High Stakes TV Game Show." Management Science 65(10): 4795-4812.

van den Assem, Martijn J., Dennie van Dolder, and Richard H. Thaler. 2012. "Split or Steal? Cooperative Behavior When the Stakes Are Large." Management Science 58(1): 2-20.

van Dolder, Dennie, Martijn J. van den Assem, Colin F. Camerer, and Richard H. Thaler. 2015. "Standing United or Falling Divided? High Stakes Bargaining in a TV Game Show." American Economic Review 105(5): 402-407.

van Veldhuizen, Roel. 2018. "Gender Differences in Tournament Choices: Risk Preferences, Overconfidence or Competitiveness?" Working paper.

Wozniak, David, William T. Harbaugh, and Ulrich Mayr. 2014. "The Menstrual Cycle and Performance Feedback Alter Gender Differences in Competitive Choices." Journal of Labor Economics 32(1): 161-98.

Zhang, Y. Jane. 2013. “Can Experimental Economics Explain Competitive Behavior Outside the Lab?" Working paper.

Zhang, Y. Jane. 2019. "Culture, Institutions and the Gender Gap in Competitive Inclination: Evidence from the Communist Experiment in China." Economic Journal 129(617): 509-552. 